\title{
Effect of high-fructose diet-induced metabolic syndrome on the pituitary-gonadal axis from adolescence through adulthood in male albino rats and the possible protective role of ginger extract. A biochemical, histological and immunohistochemical study
}

\author{
A.E. El-Mehi, M.A. Faried \\ Anatomy and Embryology Department, Faculty of Medicine, Menoufia University, Egypt \\ [Received: 9 November 2019; Accepted: 16 December 2019]
}

Background: This work was designed to clarify, for the first time up to our knowledge, the effects of high-fructose diet (HFrD)-induced metabolic syndrome (MetS) on the pituitary-gonadal axis of adolescent male rats continuing through adulthood period and to evaluate the possible role of ginger extract in ameliorating these effects.

Materials and methods: Forty 4-week-old male albino rats, treated for 8 weeks, were randomly divided into four equal groups; control (fed standard diet), ginger extract-treated (500 mg/kg once daily orally by gavage), HFrD-induced MetS (fed a diet containing $60 \%$ fructose), HFrD and ginger groups. The assessment methods included biochemical, histological and immunohistochemical studies.

Results: High-fructose diet-fed rats exhibited a picture similar to Mets in the form of increased body weight and serum levels of glucose and insulin with an elevated HOMA-IR reflecting insulin resistance as well as dyslipidaemia. Lipid peroxidation (increased malondialdehyde) and oxidative stress (decreased superoxide dismutase) were implicated in this syndrome. This group exhibited a significant decrease in testicular weight and the levels of reproductive hormones ( $L H, F S H$ and testosterone). The pituitary gonadotrophs showed electron dense nuclei, large cytoplasmic vacuoles, destructed organelles in addition to decreased number of secretory granules. Furthermore, testicular specimens presented marked alterations. There were disorganised shrunken tubules with irregular basement membranes, reduced germinal epithelial thickness, vacuolations and degenerated mitochondria in the spermatogenic cells. Beclin 1 and proliferating cell nuclear antigen immunoexpressions were significantly downregulated with HFrD-induced MetS. Ginger extract supplementation proved to be a potent protective agent against these harmful effects through its antioxidant, hypoglycaemic, insulinotropic, androgenic and hypolipidaemic effects in addition to its ability to induce testicular autophagy.

Conclusions: Consumption of HFrD induced MetS and proved to have harmful effects on the pituitary-testicular axis. Moreover, this work provided a new insight into the possible use of ginger extract to alleviate the main features of MetS and protect the pituitary-gonadal axis from the damaging effects of HFrD-induced MetS. (Folia Morphol 2020; 79, 4: 690-708)

Key words: high fructose, metabolic syndrome, ginger, pituitary, testis, oxidative stress, histopathology, immunohistochemistry

Address for correspondence: Dr. M.A. Faried, Anatomy and Embryology Department, Faculty of Medicine, Menoufia University, Egypt, e-mail: manarfaried@med.menofia.edu.eg; manarfaried@yahoo.com 


\section{INTRODUCTION}

Fructose is a simple carbohydrate present in fruits and honey. Nowadays it is extensively added to processed food and beverages because of its sweetness, palatability and taste enhancement. The consumption of high-fructose corn syrup in fruit juices, canned jams, soft drinks, breakfast cereals and candies, has increased by at least $25 \%$ during the past 30 years [76]. Unfortunately, the highest consumers of fructose are adolescents with a quarter of them consuming at least $15 \%$ of their daily caloric intake from fructose alone [83].

The administration of foods enriched with fructose is considered as one of the main factors responsible for progression to metabolic syndrome (MetS) through the induction of oxidative stress leading to hypertriglyceridaemia, insulin resistance and obesity [79]. MetS affects all biological systems including the reproductive organs [15]. Moreover, it is suggested to be related to hypogonadism and testicular dysfunction [22].

In mammals, the functional maturation of male reproductive organs is under strict regulation by hormones of the pituitary-gonadal axis. Accordingly, it is quite logical that any affection to this axis brings about a constitutional delay in the spermatogenic process [40].

Considering the magnitude of the problem, treatment of MetS is challenging. However, its management is not an easy issue as there is no established drug treatment to prevent or improve the syndrome as a whole [10]. Herbal medicines have proven therapeutic effects on regulating blood glucose, lipid profile, and blood pressure. This means herbal medicines have the potential to be alternative or complementary medicines for MetS [34].

Ginger (Zingiber officinale), one of the most commonly used spices and medicinal plants around the world, has been found to have beneficial pharmacological activities such as antioxidant, hypoglycaemic, insulinotropic, androgenic and hypolipidaemic effects $[36,70]$. The bioactive compounds of ginger include volatile oils and pungent phenol compounds such as shogaols, zingerone and gingerols in addition to vitamins such as $A, B, C$ and $E$ as well as flavonoids and glutathione [68].

There is growing evidence indicating that ginger exerts beneficial effects against obesity and related metabolic changes [28]. Moreover, Abarikwu et al. [1] recorded the protective role of phenolic acids and flavonoid compounds on testicular androgenesis and spermatogenesis.

With these facts in mind, this work was designed to investigate, for the first time up to our knowledge, the impact of high-fructose diet (HFrD)-induced MetS, starting at the adolescent period extending throughout adolescence and into adulthood, on the pituitary-testicular axis of rats and the possible ameliorating effect of ginger extract on these changes.

\section{MATERIALS AND METHODS}

\section{Animals}

Forty male Sprague-Dawley rats aged 4 weeks at an average weight of 60-70 $\mathrm{g}$ were used in this study. They were obtained from the National Centre of Researches (Cairo, Egypt) and maintained in the animal house of the Faculty of Medicine, Cairo University, Egypt. Animals were maintained at room temperature of $25-27^{\circ} \mathrm{C}$ under $12 \mathrm{~h}$ light/dark cycles and allowed free access to chow and water. All procedures were accepted by the Animal Care and Use Committee, Faculty of Medicine, Menoufia University, Egypt. This was in strict accordance with the requirement of National Research Council 2011 (Guide for the Care and Use of Laboratory Animals: Eighth Edition. Washington, DC: The National Academies Press).

\section{Experimental substances}

Diet formulation. The control diet consisted of: $60 \%$ corn starch, $20 \%$ casein, $0.7 \%$ methionine, $5 \%$ groundnut oil, $10.6 \%$ wheat bran, $3.5 \%$ salt mixture and $0.2 \%$ vitamin mixture. The HFrD contained $60 \%$ of fructose (Safety Misr, Specialized Food Industry Co., Cairo, Egypt) instead of corn starch with the remaining composition being the same as that of the control diet [21]. Both diets were prepared at the National Research Centre, El-Doki, Cairo, Egypt.

Ginger was available as tablets (400 $\mathrm{mg}$ ginger extract/tablet) stored at a temperature not exceeding $30^{\circ} \mathrm{C}$. The tablets were crushed and dissolved in distilled water. The form used in this study was a product of Arab Co. for Pharmaceuticals and Medicinal Plants "MEPACO-MEDIFOOD", Egypt.

\section{Experimental design}

The rats were acclimatised for 1 week and were provided with the standard diet and water before the dietary intervention. Rats were randomly divided into four groups (10 rats each) and treated as follows (for 8 weeks): 
- Group I (control): rats were provided with control diet;

- Group II (ginger treated): rats were provided with control diet with once daily administration of ginger extract ( $500 \mathrm{mg} / \mathrm{kg}$ ) orally by gavage;

- Group III (HFrD-induced MetS): rats were provided with HFrD ad libitum;

- Group IV (HFrD + ginger): rats were fed with HFrD with once daily administration of ginger extract ( $500 \mathrm{mg} / \mathrm{kg}$ ) orally by gavage.

\section{Specimen collection}

At the end of the experimental period, the rats were weighed, fasted overnight and blood samples were obtained from the retro-orbital venous plexus, collected in dry sterile tubes and allowed to clot for $60 \mathrm{~min}$. Sera were obtained by centrifugation at $3000 \mathrm{~g}$ for $15 \mathrm{~min}$ and stored at $-70^{\circ} \mathrm{C}$ until the time of analysis. Rats were sacrificed under light ether anaesthesia. The pituitary glands and testes were quickly excised. The testes were weighed. The tissues were processed for biochemical and/or histological and immunohistochemical analyses. The right testes were processed for biochemical study and the left for histopathological study.

\section{Evaluation methods}

\section{Total body and testicular weight assessment}

At the end of the experiment, total body weight, absolute and relative [testis weight $(\mathrm{g}) /$ body weight (g) $\times 100]$ testicular weight were assessed.

\section{Biochemical assessment}

Estimation of serum parameters and insulin resistance. Serum levels of glucose, insulin, high-density lipoprotein (HDL), low density lipoprotein (LDL) and triglycerides (TG) were tested using the commercially available kits and according to the manufacturer's instructions.

The homeostasis model assessment for insulin resistance (HOMA-IR) was used to estimate insulin sensitivity. The formula used to calculate HOMA-IR is: HOMA-IR $=$ [fasting insulin $(\mu \mathrm{U} / \mathrm{mL})] \times$ [fasting glucose $(\mathrm{mg} / \mathrm{dL}) / 405]$.

Assessment of lipid peroxidation and tissue antioxidant status. The right testes of rats were immediately frozen at $-70^{\circ} \mathrm{C}$. Frozen tissue was homogenised in ice-cold phosphate buffer $(\mathrm{KCl} 140 \mathrm{mmol} / \mathrm{L}$, phosphate $20 \mathrm{mmol} / \mathrm{L}, \mathrm{pH} 7.4$ ) and centrifuged at
$10000 \mathrm{~g}$ for $15 \mathrm{~min}$. The supernatant was used for the measurement of tissue superoxide dismutase (SOD) and malondialdehyde (MDA).

Estimation of reproductive indices. The circulatory levels of the pituitary and testicular hormones (follicular stimulating hormone [FSH], luteinizing hormone [ $\mathrm{LH}]$ and testosterone) were assayed using available commercial enzymes immunoassay kits specific for rats according to the instructions of the manufacturer.

\section{Histological examination}

Light microscopic study. Pituitary glands and testicular specimens were immediately fixed in Bouin's solution for $24 \mathrm{~h}$, dehydrated in ascending grades of alcohol, cleared and embedded in paraffin. Sections of 5 microns thick were cut by microtome and subjected to haematoxylin and eosin (H\&E) staining for routine histological assessment.

Transmission electron microscopic (TEM) study. Small pieces of testes and pituitary glands were fixed in 3\% glutaraldehyde for electron microscopic examination. After fixation, they were postfixed in $1 \%$ osmium tetraoxide and dehydrated. After embedding in epoxy resin, ultrathin sections (50-80 nm thick) were cut with ultramicrotome, collected on copper grids and stained with lead citrate and uranyl acetate. The grids were examined and photographed by transmission electron microscope.

\section{Immunohistochemical staining}

The deparaffinised and rehydrated $5-\mu \mathrm{m}$ sections were rinsed with phosphate buffer solution (PBS), blocked in $3 \% \mathrm{H}_{2} \mathrm{O}_{2}$ as an inhibitor of endogenous peroxidase activity. After rinsing in PBS, The microwave antigen retrieval procedure was performed. The sections were then incubated with the primary antibody: proliferating cell nuclear antigen (PCNA) (1:100, mouse monoclonal, Abcam), and beclin 1 (1:200, rabbit polyclonal, Abcam) at room temperature for an hour. Sections were rinsed with PBS, followed by $20 \mathrm{~min}$ of incubation at room temperature with secondary biotinylated antibody. After rinsing the sections in PBS, enzyme conjugate "Streptavidin-Horseradish peroxidase" solution was applied to the sections for $10 \mathrm{~min}$. Secondary antibody binding was visualised using 3,3-diaminobenzoic acid (DAB). Finally, sections were PBS rinsed and counterstaining of slides was done using two drops of haematoxylin. 
Table 1. Weight (body and testicular) and biochemical parameters of the different groups (mean \pm standard deviation)

\begin{tabular}{llccc}
\hline Parameter & & Control & HFrD & HFrD + Ginger \\
\hline Weight [g] & Body & $204.34 \pm 2.93$ & $241.01 \pm 2.47^{*}$ & $220.34 \pm 2.62 \#$ \\
& Absolute (TW) & $2.08 \pm 0.07$ & $1.01 \pm 0.03$ & $1.52 \pm 0.05^{*}$ \\
& Relative (TW) & $0.65 \pm 0.02^{*}$ & $1.88 \pm 0.05 \#$ & $0.87 \pm 0.03 \#$ \\
Lipid profile [md/dL] & TG & $65.15 \pm 2.70$ & $127.73 \pm 3.62^{*}$ & $81.82 \pm 1.91 \#$ \\
& LDL & $46.63 \pm 1.11$ & $75.33 \pm 1.81^{*}$ & $58.15 \pm 2.02 \#$ \\
Plasma & HDL & $43.98 \pm 1.01$ & $22.55 \pm 1.37^{*}$ & $34.55 \pm 1.28 \#$ \\
Glucose-Insulin & Glucose [mg/dL] & $81.99 \pm 1.79$ & $118.80 \pm 2.49^{*}$ & $96.07 \pm 2.27 \#$ \\
& Insulin $[\mu \mathrm{U} / \mathrm{mL}]$ & $16.45 \pm 1.08$ & $31.84 \pm 1.29^{*}$ & $20.38 \pm 0.99 \#$ \\
Reproductive hormones & HOMA-IR & $3.33 \pm 0.24$ & $9.34 \pm 0.56^{*}$ & $4.83 \pm 0.32 \#$ \\
& Testosterone [ng/dL] & $4.23 \pm 0.29$ & $1.94 \pm 0.04^{*}$ & $3.02 \pm 0.06 \#$ \\
Tissue oxidative markers & FSH [mlU/mL] & $3.18 \pm 0.16$ & $1.76 \pm 0.22^{*}$ & $2.60 \pm 0.16 \#$ \\
& LH [mlU/mL] & $2.49 \pm 0.27$ & $1.08 \pm 0.06^{*}$ & $2.08 \pm 0.06 \#$ \\
\hline
\end{tabular}

${ }^{*} \mathrm{P}<0.001$ comparing HFrD to the control group; $\# \mathrm{p}<0.001$ comparing HFrD + ginger to the HFrD group; TW - testicular weight; other abbreviation - see text

\section{Quantitative assessment}

Using Image J software, version K 1.45 , the following parameters were measured:

- the perimeter of seminiferous tubules and the height of their lining epithelium: the mean perimeter was obtained for each animal from the measurement of 30 cross sections of circular, as possible, seminiferous tubules. The height of epithelium was measured, as the distance from the basement membrane to the tubular lumen, in the same tubules at four sites at right angles;

- the percentage of PCNA immunopositive cells and area $\%$ of Beclin 1 immunoreaction: for each parameter, ten non-overlapping fields $(40 \times)$ for every specimen, randomly taken using a Leica DML B2/11888111 microscope equipped with a Leica DFC450 camera, from five different rats/ lexperimental group were examined.

\section{Statistical analysis}

The collected data were presented as mean \pm standard deviation. Data analysis was performed using SPSS (statistical package for social science) version 23.0. The obtained data were analysed using one-way ANOVA and the differences among groups were determined by Bonferroni test as post hoc. A p value of $<0.05$ was considered statistically significant.

\section{RESULTS}

As there was no significant difference detected, regarding the all examined parameters, between the control and ginger-treated groups, the two groups were pooled into one group "control group".

\section{Body weight and testicular weight}

High-fructose diet-fed rats exhibited a significant increase $(p<0.001)$ in the body weight when compared to controls. Absolute and relative testicular weights were significantly reduced $(p<0.001)$ in HFrD group compared to the control group. Ginger administration significantly decreased the total body weight and increased the testicular weight compared to HFrD untreated group ( $p<0.001$ ) (Table 1).

\section{Biochemical results}

Serum parameters and insulin resistance. Increased serum levels of glucose and insulin with a subsequent elevation of HOMA-IR ( $p<0.001)$ were detected in the HFrD group compared to the control group. Also, increased levels of serum TG, LDL, and decreased levels of HDL ( $p<0.001$ ) were detected. HFrD rats treated with ginger, on the other hand, showed a significant restoration $(p<0.001)$ of these serum parameters compared to their untreated counterparts (Table 1). 
Lipid peroxidation and tissue antioxidant status. HFrD fed rats showed a significant decrease $(p<0.001)$ in the testicular tissue levels of antioxidant marker SOD, and increase $(p<0.001)$ in the MDA concentration compared to the control rats. Ginger administration to HFrD rats resulted in a significant rise in SOD, and decrease in the MDA levels $(p<0.001)$ in comparison with the HFrD group (Table 1).

Reproductive indices. HFrD feeding resulted in a significant decrease $(p<0.001)$ in FSH, LH and testosterone hormones, when compared to the control group. Ginger supplementation produced a significant increase $(p<0.001)$ in the levels of these hormones compared to HFrD group (Table 1).

\section{Histological results}

\section{Pituitary gland}

Light microscopic examination. H\&E-stained sections from the control group revealed normal histological architecture of the pituitary gland. It was formed of cellular cords and clusters separated by blood sinusoids. Three types of cells could be identified; acidophils (red-coloured cytoplasm and rounded nuclei), basophils (basophilic cytoplasm and dark oval nuclei) and chromophobes (rounded cells with centrally located nuclei). Sections from HFrD-induced MetS group exhibited distorted architecture, cellular vacuolations and increased intercellular spaces. Ginger administration resulted in significant restoration of the normal histological picture (Fig. 1A-C).

Transmission electron microscopic examination. The pituitary gonadotrophs of the control rats had oval or rounded euchromatic nuclei. The cytoplasm contained secretory granules of variable size and electron density. Moreover, the cytoplasm showed well developed Golgi bodies, rough endoplasmic reticulum ( $r E R$ ) and mitochondria. In HFrD-induced MetS group, gonadotrophs showed electron dense nuclei with clumps of heterochromatin. The cytoplasm showed numerous large vacuoles, destructed mitochondria, dilated rER in addition to decreased number of secretory granules. Ginger supplementation produced obvious improvement of gonadotrophs to become more or less similar to those of the control group except for slight decrease in its secretory granules (Fig. 1D-F).

\section{Testis}

Light microscopic examination. H\&E-stained testicular sections of the control group showed closely packed regularly organized seminiferous tubules separated by a narrow interstitium containing clusters of interstitial Leydig cells. The tubules were lined by stratified germinal epithelium formed of germ cells of various stages of differentiation; spermatogonia, primary spermatocytes, spermatids in addition to the supporting Sertoli cells. Spermatozoa were seen in the lumina of the tubules (Fig. 2A).

Examination of sections of the HFrD-induced MetS group showed disorganised shrunken seminiferous tubules with a significant reduction $(p<0.001)$ of their average perimeter comparable to controls. Also, the lining germinal epithelium showed focal separation from the basement membrane, significant reduction in thickness when compared to the control ( $p<0.001)$, and many cells with vacuolated cytoplasm and wide intercellular spaces. The lumina of the tubules contained acidophilic hyalinised material and a few spermatozoa. The interstitium appeared widened with vacuolated cytoplasm, congested blood vessels and deposition of homogenous acidophilic material (Figs. 2B-E; 3).

Whereas, HFrD-induced MetS group treated with ginger extract showed obvious improvement of the testicular histoarchitecture and morphometric examined parameters approaching that of control except for slight vacuolation within the interstitium (Figs. 2F; 3).

Transmission electron microscopic examination. The testes of the control group showed seminiferous tubules ensheathed by regular basement membranes and flat myogenic cells. Sertoli cells appeared resting on the basement membrane and had oval folded euchromatic nuclei with prominent nucleoli and well developed organelles. Spermatogonia were closely related to basement membrane and had rounded nuclei. Spermatocytes were distinguished by their large rounded nuclei. The spermatid's nucleus was rounded, euchromatic and contained a small rounded clump of heterochromatin. The cytoplasm exhibited small peripherally located mitochondria. Spermatids with distinct nuclear acrosomal caps were also observed. The interstitial Leydig cells had indented euchromatic nuclei with peripheral heterochromatin clumps. The cytoplasm had multiple processes and contained well-developed mitochondria and numerous $s E R$. Cross sections in the mid piece of the sperm's tail showed a central axoneme surrounded by nine electron dense bundles of fibrous sheath, mitochondrial sheath and cell membrane (Fig. 4A-F). 
Control
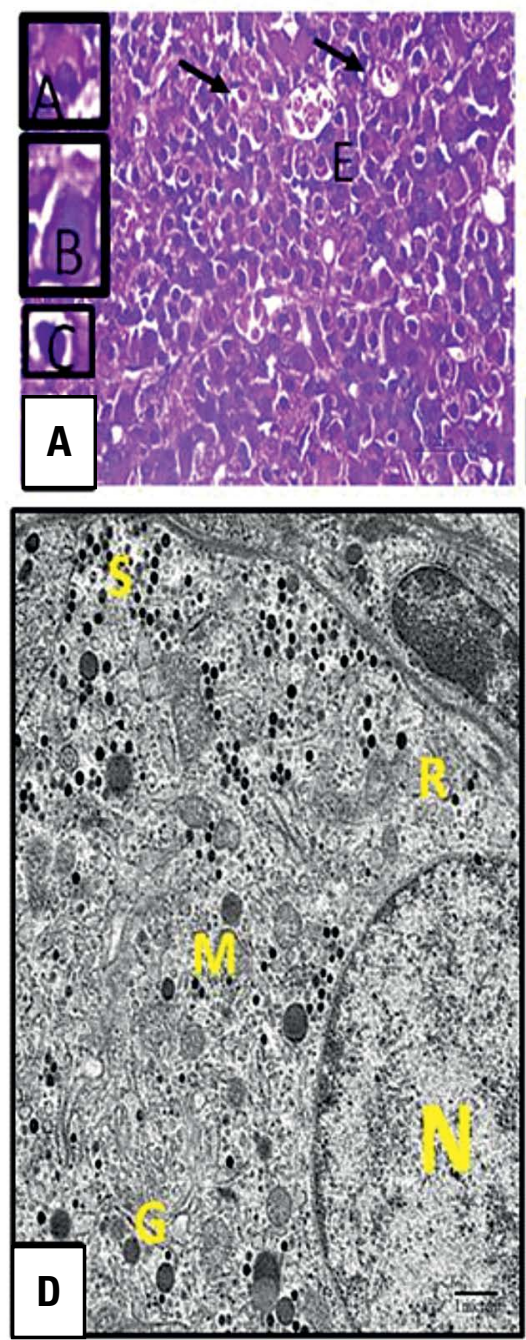

HFrD
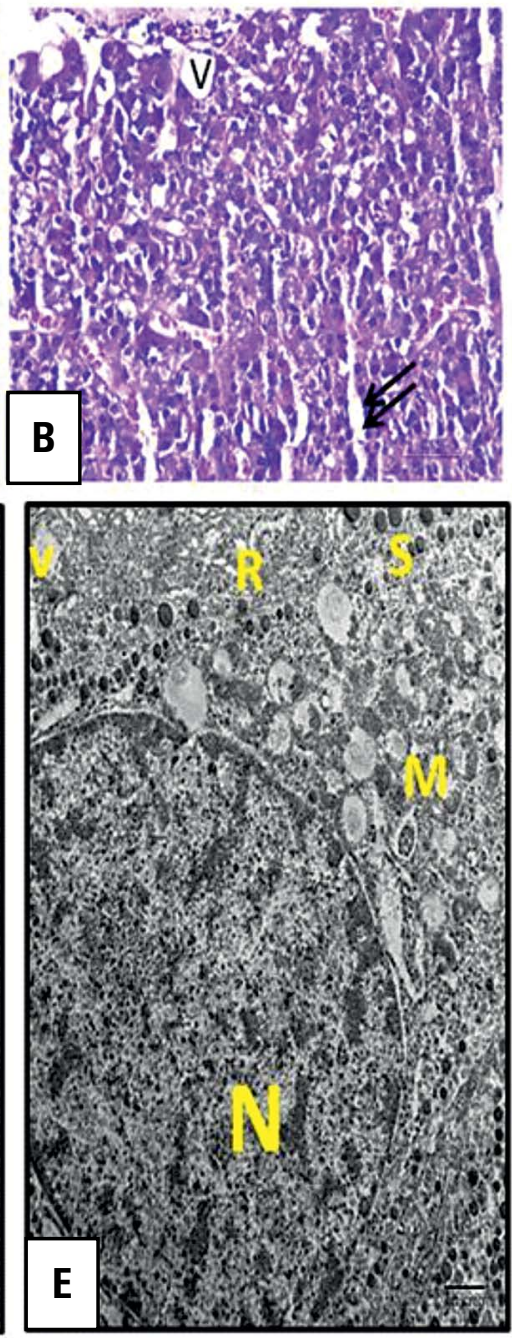

HFrD + Ginger
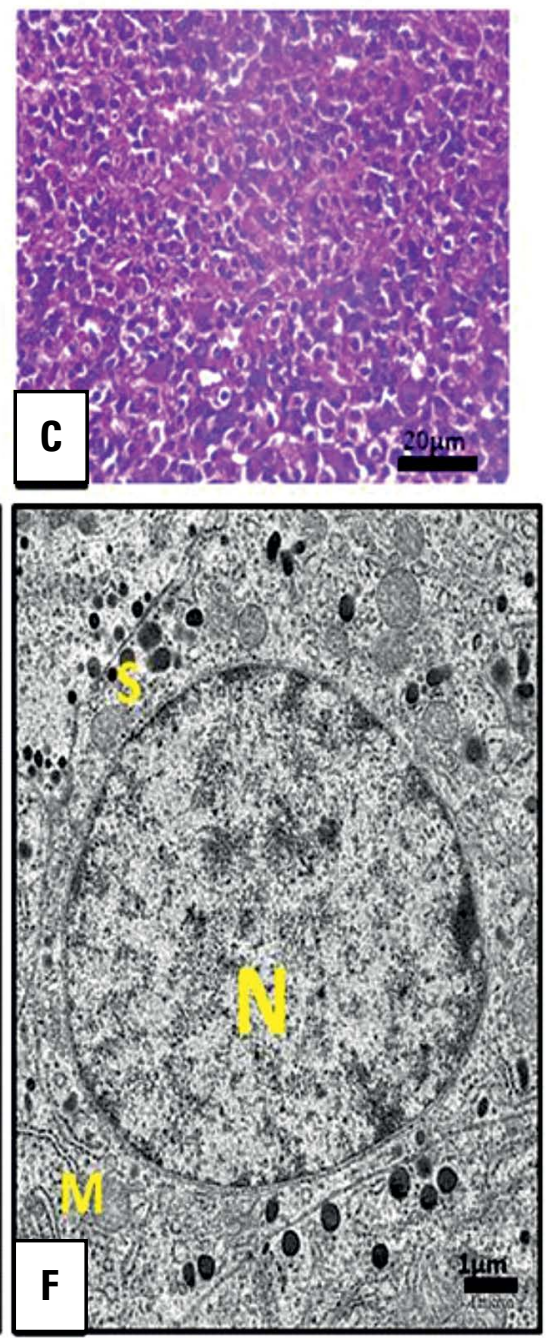

Figure 1. A-C. Representative micrographs of haematoxylin and eosin (H\&E)-stained sections of the anterior pituitary of the different studied groups; A. Control group showing normal pituitary endocrine cells (E) arranged in groups and surrounded by blood sinusoids (arrows). Note: acidophil (A), basophil (B) and chromophobes (C) cells; B. High-fructose diet (HFrD) group showing disrupted architecture with appearance of many vacuoles (V) and widening of intercellular spaces (double arrows); C. Most of pituitary cells in the rats receiving HFrD + ginger revealing more or less restoration of normal architecture (H\&E 40×, scale bar $=20 \mu \mathrm{m}$ ); D-F. Representative electron micrographs of the gonadotroph of the different studied groups; D. A gonadotroph cell of the control group showing an euchromatic nucleus (N), well developed mitochondria (M), Golgi body (G) and rough endoplasmic reticulum ( $r E R)(R)$ as well as numerous secretory granules $(S)$ of variable size and density; $\mathrm{E}$. A gonadotroph cell of $\mathrm{HFrD}$ group exhibiting a nucleus with chromatin condensation (N), rarified cytoplasm with many large vacuoles (V), degenerated mitochondria with destructed cistern (M) and dilated rER (R). Note apparent decrease in the number of the secretory granules (S); F. A gonadotroph of the rats receiving HFrD + ginger revealing normal nucleus $(\mathrm{N}$ ) and well developed organelles as mitochondria (M). Note: apparent slight decrease in the number of its secretory granules (s). (TEM $\times 17500$, scale bar $=1 \mu \mathrm{m}$ ).

Sections of the HFrD-induced MetS group showed irregularities of the basement membranes surrounding most of the seminiferous tubules. Sertoli cells showed large lipid droplets, vacuolations and degenerated mitochondria within their cytoplasm. Spermatogonia had shrunken heterochromatic nuclei with irregular nuclear envelopes and many large cytoplasmic vacuolations. Primary spermatocytes showed nuclear lysis and disintegrated nuclear membrane. Some spermatids appeared low in position being close to the basement membrane. The intercellular spaces between germ cells as well as the interstitium appeared widened. The interstitial Leydig cells exhibited destructed mitochondria and 

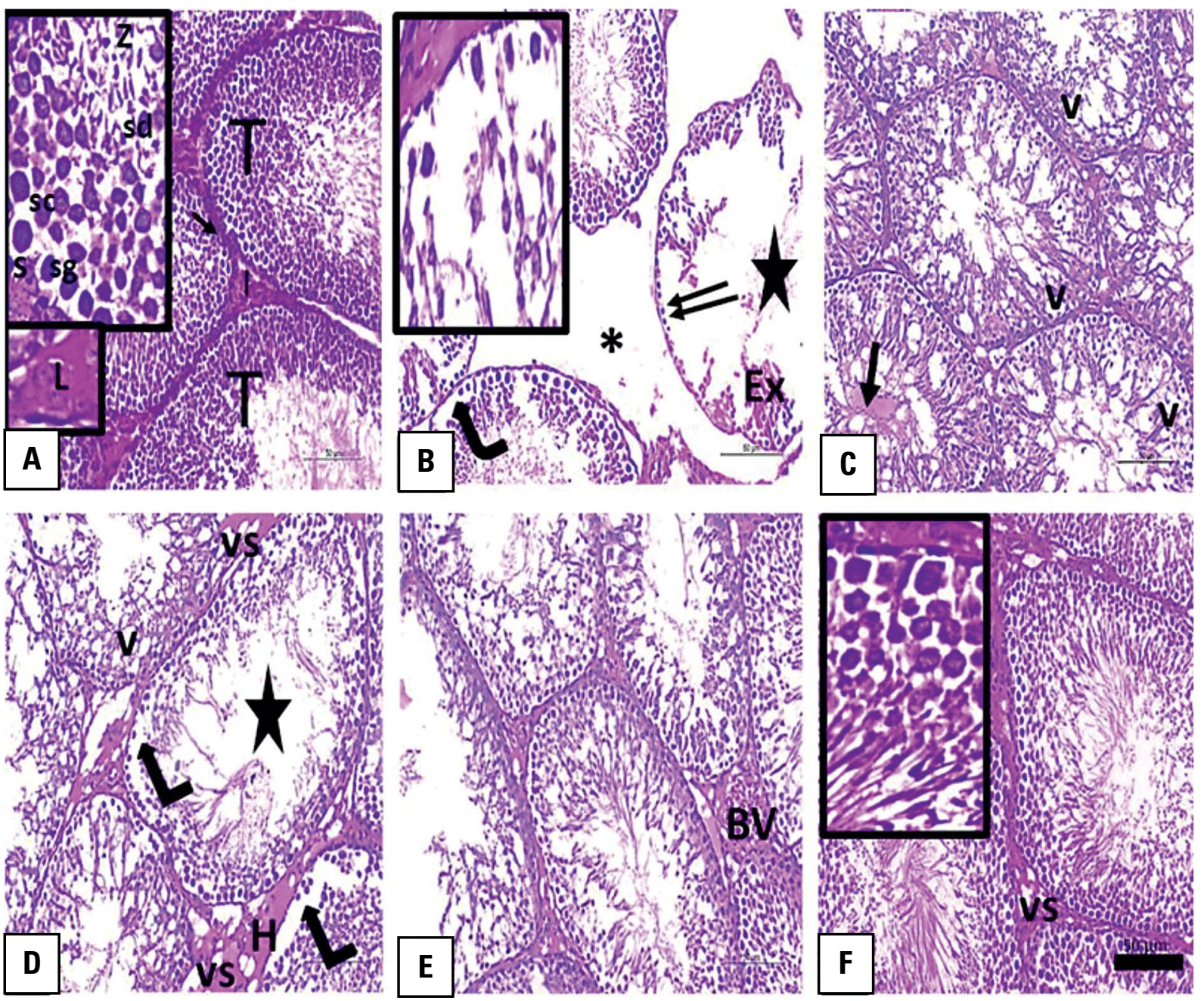

Figure 2. Representative micrographs of haematoxylin and eosin (H\&E)-stained testicular sections of the different studied groups; A. Control group showing seminiferous tubules $(\mathrm{T})$ surrounded by basement membrane (arrow) and lined with normally arranged different spermatogenic cells; spermatogonia $(\mathrm{Sg})$, primary spermatocytes $(\mathrm{Sc})$ and spermatids $(\mathrm{Sd})$. Sertoli cell $(\mathrm{S})$ is seen resting on the basement membrane and the tubular lumen is filled with spermatozoa (Z). The interstitium (I) contains a group of Leydig cells (L); B-E. High-fructose diet group showing an area of marked separation $\left({ }^{*}\right)$ between the seminiferous tubules as well as disorganisation, disruption and even loss (double arrows) of most of spermatogenic cells, separation of the spermatogenic cells from the basement membrane (bent arrows), vacuolated cytoplasm (v) with extravasation (Ex) and deposition of acidophilic hyalinized material (arrow) within the tubules. Entire loss of most of spermatozoa (star) is also noted. The interstisium is observed exhibiting many vacuoles (vs), deposition of acidophilic hyalinized material $(\mathrm{H})$ and dilated congested blood vessels (BV); F. High-fructose diet with ginger extract displaying more or less well organised spermatogenic cells. Some vacuoles (vs) within the interstitium are still present (H\&E $20 \times$, scale bar $=50 \mu \mathrm{m}$; inserts $40 \times)$.

cytoplasmic vacuoles. Cross sections in the middle pieces of sperms showed severely destructed mitochondrial sheath and excess retained vacuolated cytoplasm (Figs. 5, 6).

Ginger administration to HFrD-induced MetS group showed observable improvement of testicular tissue. However, irregular basement membrane and some separation between the germ cells were occasionally encountered. Moreover, some cells with cytoplasmic vacuolations and destructed mitochon- dria as well as retained cytoplasm surrounding normal axoneme were observed (Fig. 7).

\section{Immunohistochemical results}

Immunohistochemical analysis revealed that testicular sections from HFrD-induced MetS group showed a significant decrease $(p<0.001)$ in PCNA and Beclin 1 immunoreactivity as compared to control. These decreases were significantly increased $(p<0.001)$ by ginger supplementation (Fig. 8 ). 


\begin{tabular}{lccc}
\hline Parameter & Control & HFrD & HFrD + Ginger \\
\hline Epithelial height $[\mu \mathrm{m}]$ & $39.01 \pm 0.84$ & $20.11 \pm 1.30^{*}$ & $33.23 \pm 0.75^{\#}$ \\
Seminiferous tubule perimeter $[\mu \mathrm{m}]$ & $581.88 \pm 11.22$ & $450.76 \pm 6.51^{*}$ & $537.07 \pm 2.82^{\#}$ \\
\hline
\end{tabular}

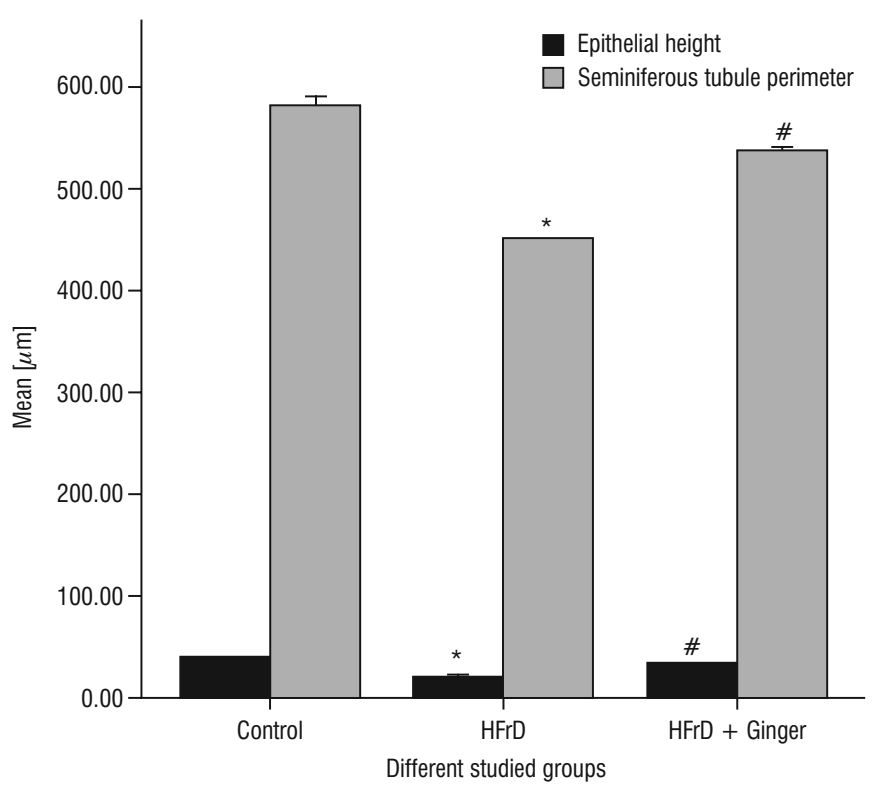

Figure 3. A histogram showing the mean epithelial height and seminiferous tubular perimeter of the different studied group; ${ }^{*} p<0.001$ comparing the high-fructose diet (HFrD) with the control; ${ }^{\#} \mathrm{p}<0.001$ comparing the HFrD + Ginger with the HFrD. Note: the table demonstrates the mean and standard deviation (SD) of the different groups.

\section{DISCUSSION}

The wide spread of MetS is becoming a crucial health problem and hence the need to develop new treatments against this syndrome and its consequences is increasing fast [54]. The worldwide prevalence of MetS emerged not only as a predictor of cardiovascular disease but also as a potential contributing factor to male infertility [82].

In this study, administration of HFrD at $60 \%$ fructose concentration was found to cause significant increase in body weight, plasma glucose, insulin, TG and LDL as well as decrease in HDL. Also, HOMA-IR, an indicator of insulin resistance, was significantly increased. Our findings, thus, proved that fructose administration at this concentration and period produces an experimental model similar to MetS. This was in accordance with Johnson et al. [35], Aydin et al. [15], Mamikutty et al. [50], and Guzmán-Gerónimo et al. [30] who demonstrated a relation between high fructose intake and MetS both in human and animal studies. Aydin et al. [15] and Mamikutty et al. [50] confirmed that rats fed with an HFrD (10-60\%) can be used as an adequate animal model for human MetS.
The adolescent age was chosen for this study as the adolescents are the top consumers of high-fructose corn syrup sweetened beverages with increasing incidence in its metabolic consequences as postulated by Alten et al. [11]. Moreover, Al-Hamad and Raman [8] stated that the prevalence of MetS in adolescents is increasing in parallel with the increasing trends of obesity rates. Harrell et al. [31] added that rats fed the HFrD during adolescent development appeared uniquely susceptible to metabolic abnormalities relative to rats fed the diet during adulthood only.

As the adolescent period is considered as a critical period of development, the hormonal changes that occur during adolescence including the increase in adrenal hormones, and the pubertal increase in gonadal hormones may be somewhat responsible for the vulnerability of this period [73].The pituitary-gonadal axis regulates the different stages of reproductive activities, such as sexual behaviour, spermatogenesis, and fertility [51]. Accordingly, we hypothesized that the adverse effects of HFrD-induced MetS on male reproductive functions might be mediated through alterations in the pituitary-gonadal axis. 

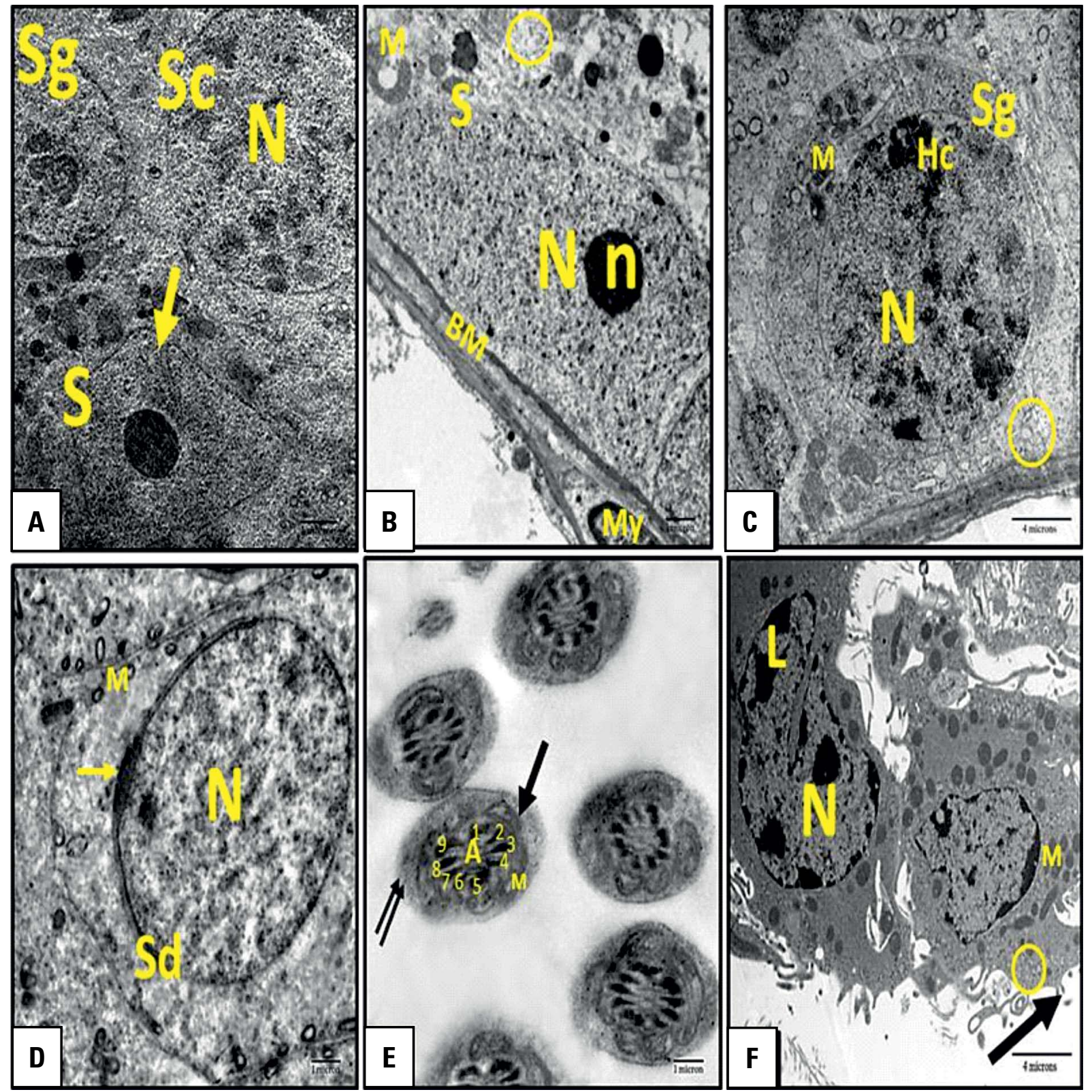

Figure 4. Representative electron micrographs of the testis of the control group; A. Showing a part of a seminiferous tubules with its lining cells; Sertoli cell $(\mathrm{S})$ with nuclear indentation (arrow), spermatogonia $(\mathrm{Sg})$ and the largest one is the primary spermatocyte (Sc) with a rounded nucleus (N) containing fine chromatin; B. Revealing the Sertoli cell (S) with an oval euchromatic nucleus (N) and prominent nucleolus (n). Its cytoplasm contains numerous mitochondria (M) and smooth endoplasmic reticulum (circle). The Sertoli cell lies on a regular basement membrane (BM) that ensheathed by the myoid cell (My); C. A spermatogonium $(\mathrm{Sg})$ exhibits a rounded euchromatic nucleus (N) with coarse clumps of heterochromatin (Hc), numerous smooth endoplasmic reticulum (circle) and mitochondria (M); D. A spermatid (Sd) at the stage of acrosomal cap formation displays rounded nucleus (N) covered by acrosomal cap (arrow) with presence of peripherally located well-developed mitochondria (M) in its cytoplasm; $\mathrm{E}$. The middle piece of the sperm's tail with central axoneme (A) that is surrounded by nine outer dense fibres (1-9), mitochondrial sheath (arrow) and cell membrane (double arrows); F. A Leydig cell (L) has an elongated indented nucleus (N) with a rim of peripheral heterochromatin. Its cytoplasm shows cytoplasmic processes (arrow) and contains well-developed mitochondria (M) and numerous smooth endoplasmic reticulums (circle). (A, B, D, E: TEM, scale bar $=1 \mu \mathrm{m}, \times 17500$; C, F: scale bar $=4 \mu \mathrm{m}, \times 8000$ ).

The increase in body weight detected with HFrD consumption in this work could be explained by the fact that the extra HFrD increased total caloric intake, as previously reported by Aguilera-Mendez et al. [4]. Moreover, Crescenzo et al. [23] showed increased white adipose tissue in rats fed HFrD despite no difference in body weight gain. On the other hand, ginger extract administration to HFrD group was found to significantly decrease body weight when compared to rats fed HFrD alone. A recent report by Wang et 

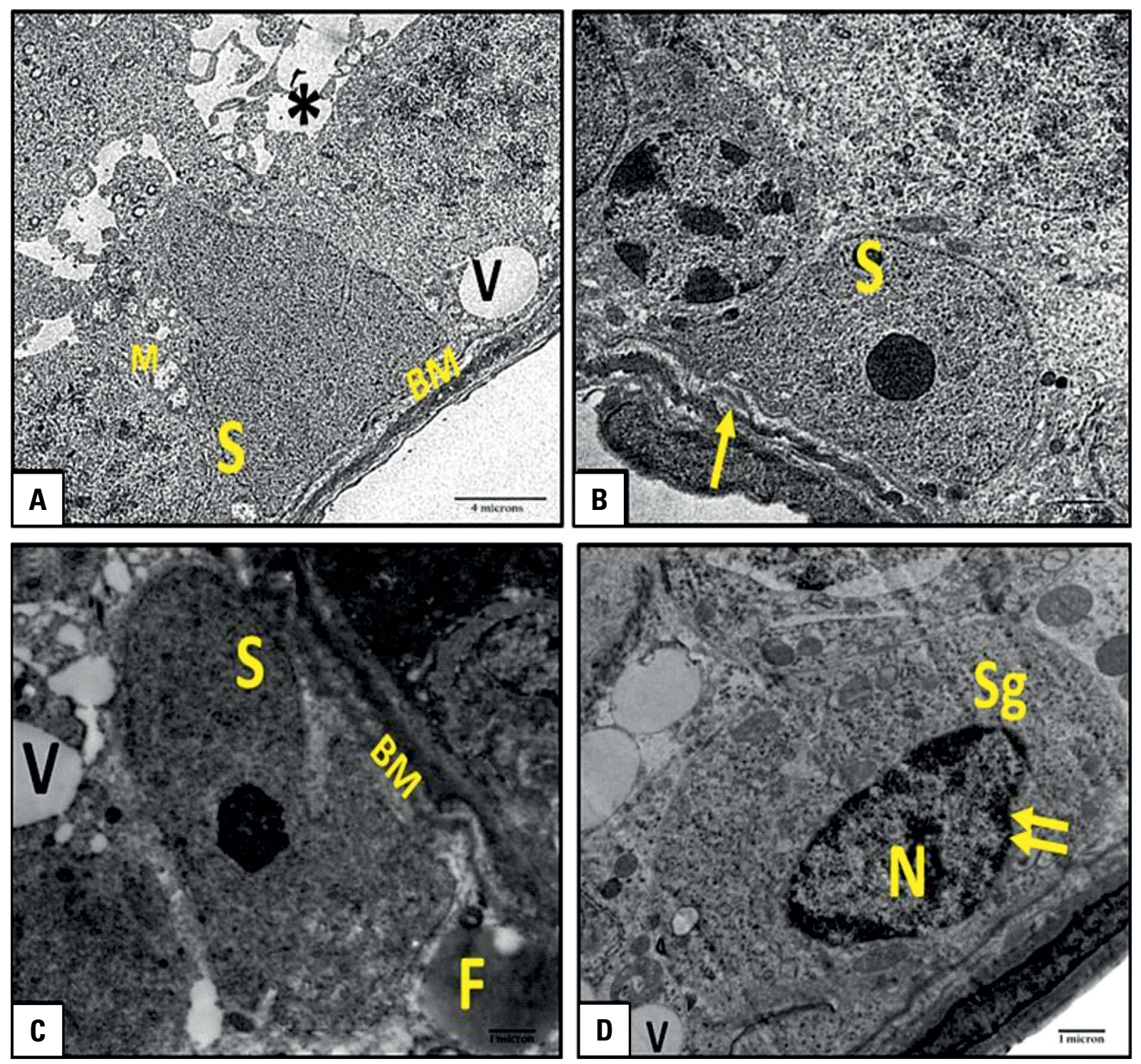

Figure 5. Representative electron micrographs of the rat testis of high-fructose diet (HFrD) group; A-C. Showing marked separation $\left({ }^{*}\right)$ between the cells. Sertoli cells (S) are based on thick irregular (arrow) basement membrane (BM). They have large vacuoles (V), degenerated mitochondria (M) and large fat droplets (F); D. Showing a spermatogonium $(\mathrm{Sg})$ with shrunken condensed nucleus (N), irregular nuclear membrane (double arrows) and multiple cytoplasmic vacuoles (V). (A: TEM, scale bar $=4 \mu \mathrm{m}, \times 8000$; B-D: scale bar $=1 \mu \mathrm{m}, \times 17500$ ).

al. [84] demonstrated that dietary ginger prevented obesity by inducing browning of white adipose tissue, thus enhancing energy expenditure, and remodelling of whole-body energy metabolism.

The characteristic features of MetS induced by HFrD, as confirmed in this study, were supported and explained previously. Dyslipidaemia, a characteristic component of MetS, was proved in this study by the significant increase in serum TG and LDL and decrease in HDL. This reproduced the results of previous studies [52, 72]. Basaranoglu et al. [17] declared that chronic fructose ingestion favours hepatic lipogenesis by pro- viding large amounts of hepatic triosephosphate as precursors for fatty acid synthesis, thus increasing lipid accumulation in the liver as well as its secretion and an increase in blood content. This can explain accumulation of lipid droplets in the cytoplasm of Sertoli cells in the present study as clarified by Meydanli et al. [52].

Hyperglycaemia, hyperinsulinaemia and insulin resistance were recorded with chronic consumption of HFrD in this study, and in conjunction with others [21]. Increased plasma concentrations of glucose may be due to decreased glucose disposal in tissues [21]. Moreover, this was explained by Prabhakar et al. [60] 

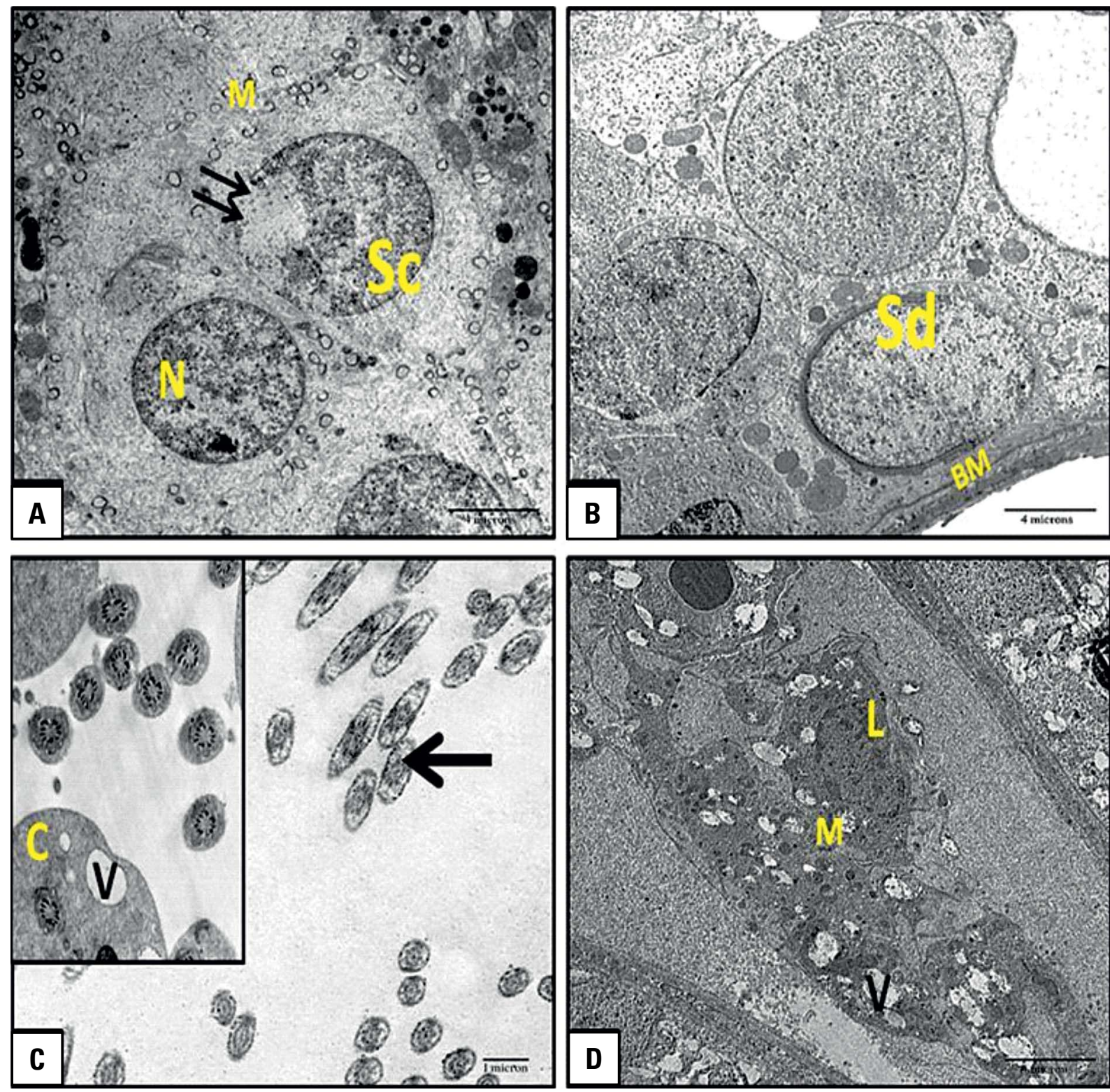

Figure 6. Representative electron micrographs of the rat testis of high-fructose diet (HFrD) group; A. Primary spermatocytes (Sc) exhibit nuclear chromatolysis (N) with partial loss of the nuclear membrane (double arrows) and degenerated mitochondria (M); B. Showing disorganisation of different spermatogenic cells in the form of resting low position of the spermatid (Sd) close to the basement membrane (BM); C. Revealing markedly degenerated axoneme (arrow) with lost/degenerated mitochondrial sheath. The insert shows the axoneme surrounded by retained excess vacuolated (V) cytoplasm (C); D. Leydig cells (L) have many vacuoles (V) and degenerated mitochondria (M). (A, B, D: TEM, scale bar $=4 \mu \mathrm{m}, \times 8000 ; \mathrm{C}$ : scale bar $=1 \mu \mathrm{m}, \times 17500)$.

who revealed that fructose stimulates gluconeogenesis in male rats. Further, fructose feeding decreases the efficacy of insulin extraction by the liver, which retards insulin clearance from the circulation as declared by Suga et al. [74]. Indeed, Tappy and Lê [78] postulated that dyslipidaemia, in response to HFrD, can lead to insulin resistance by reducing the insulin signalling pathway.
Carrier [19] clarified that there was a great link between oxidative stress and MetS pathophysiology. This was confirmed in this study by the significant increase in MDA, a sensitive biomarker of lipid peroxidation, with significant decrease in the antioxidant enzyme SOD in testicular homogenates of HFrD rats, clearly indicating oxidative stress and impaired lipid metabolism. Similar results were recorded in the liv- 

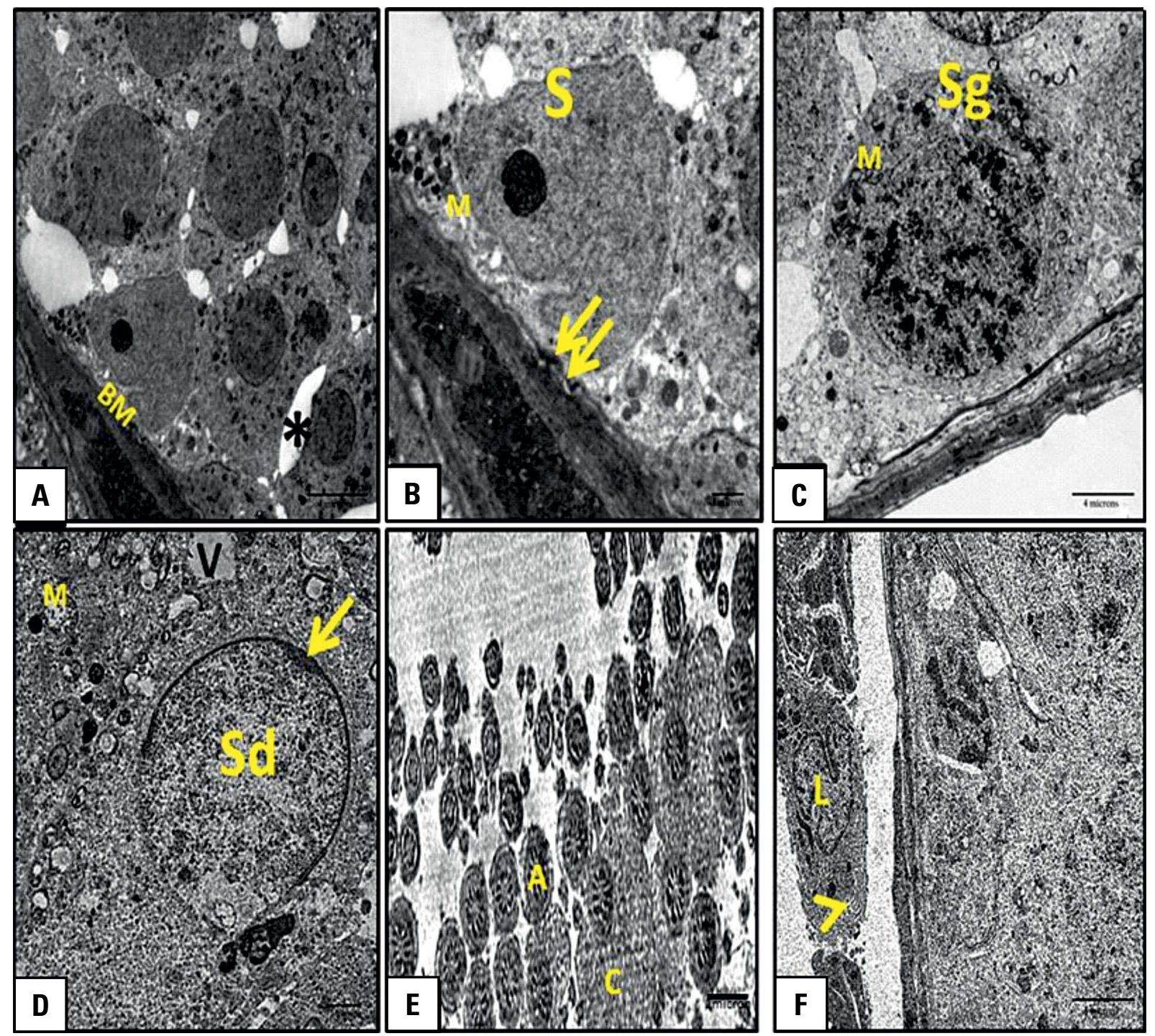

Figure 7. Representative electron micrographs of the rat testis receiving high-fructose diet (HFrD) + ginger extract; A. Showing more or less normal spermatogenic organisation resting on the basement membrane (BM). Slight separation (asterisk) between the cells is still noted; B. Showing a normal Sertoli cell (S) with well-developed mitochondria (M) based on a slightly irregular (double arrows) basement membrane; C. Showing a well-developed spermatogonium $(\mathrm{Sg})$ with normal mitochondria $(\mathrm{M})$; $\mathbf{D}$. Revealing more or less normal spermatid (Sd) with acrosomal cap (arrow). A few degenerated mitochondria (M) and slight vacuolations (V) are observed within its cytoplasm; E. Showing normal appearance of the midpieces of sperms with central axoneme (A). However, some exhibit retained cytoplasm (C); F. Dilated rough endoplasmic reticula (arrow head) are noted within more or less well organised Leydig cell (L). (A, C, F: TEM, scale bar $=4 \mu \mathrm{m}, \times 8000$; $\mathrm{B}, \mathrm{D}, \mathrm{E}$ : scale bar $=1 \mu \mathrm{m}, \times 17500)$.

er [72], the kidney [81], the heart and aorta [61] of $\mathrm{HFrD}$ fed rats. This was attributed to altered cellular metabolism with overproduction of reactive oxygen species (ROS) and simultaneous decline of antioxidant defence mechanisms as explained by Chandramohan and Pari [21]. Sharma and Agarwal [71] clarified that spermatozoa are characterised by the high content of polyunsaturated fatty acids within their plasma membrane thus being highly susceptible to damage by excessive concentrations of ROS. They added that lipid peroxidation destroys the lipid matrix in the membranes of spermatozoa, and this is associated with loss of motility and impairment of spermatogenesis.

Moreover, there were significantly decreased circulating levels of pituitary hormones $\mathrm{FSH}$ and $\mathrm{LH}$, in this work, following HFrD consumption. These results reflect impaired pituitary function which goes in accordance with the histopathological alterations observed in the pituitaries of the HFrD-induced MetS group. Many gonadotrophs showed destructed mitochondria and 

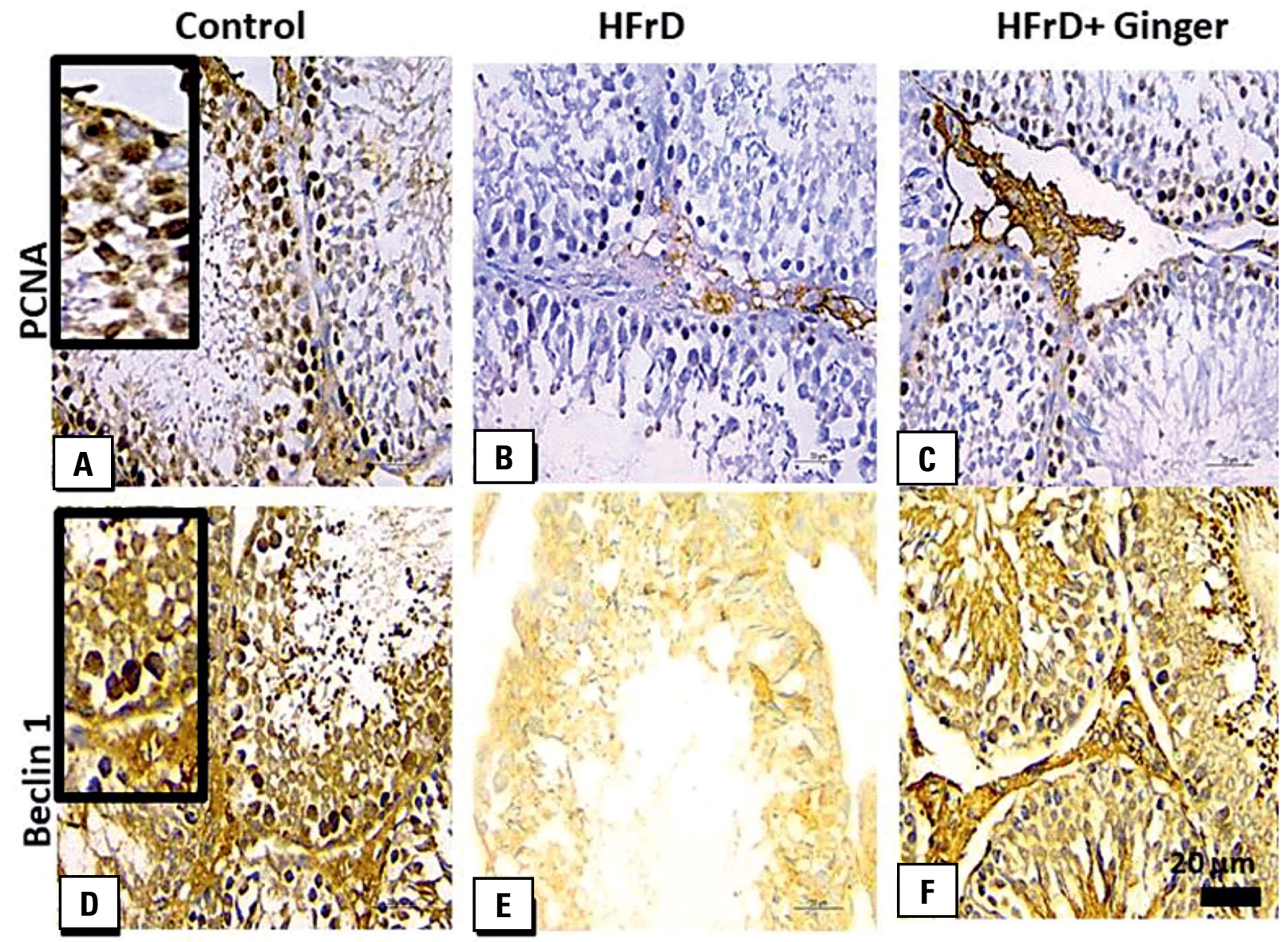

\begin{tabular}{lccc}
\hline Parameter & Control & HFrD & HFrD + Ginger \\
\hline PCNA immunopositive cells (\%) & $82.48 \pm 0.71$ & $33.12 \pm 2.19^{*}$ & $74.60 \pm 1.51^{\#}$ \\
Beclin 1 immunoreaction (area \%) & $55.48 \pm 1.61$ & $20.31 \pm 1.28^{*}$ & $52.44 \pm 1.25^{\#}$ \\
\hline
\end{tabular}

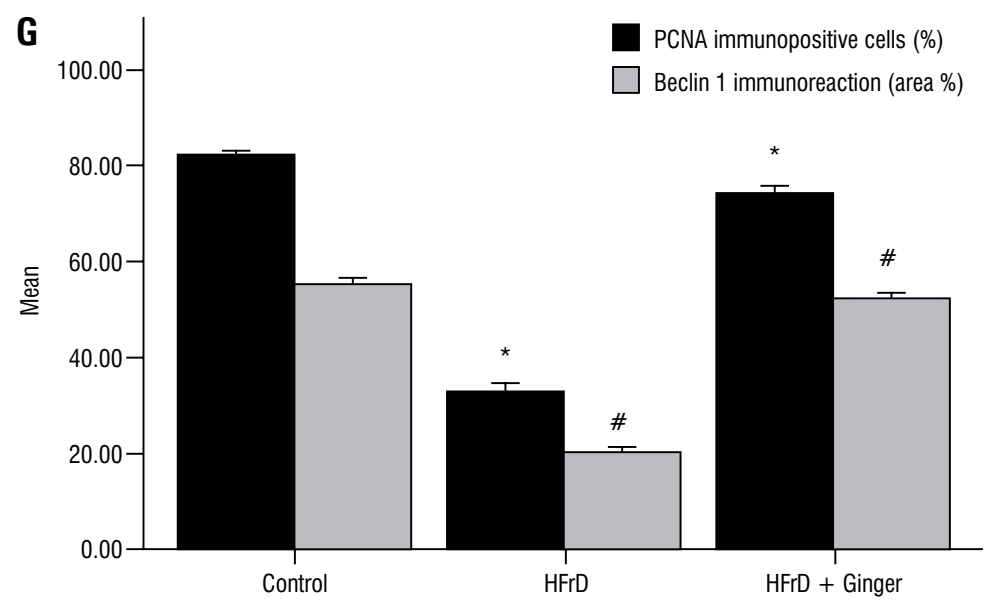

Figure 8. A-F. Representative immunostaining micrographs of rats' testicular sections of the different studied groups showing decreased proliferating cell nuclear antigen (PCNA) (A-C) and beclin 1 (D-F) immunoreaction of high-fructose diet (HFrD) group compared to the control. However ginger administration restored the immunoreaction approaching the control (immunostaining $40 \times$, scale bar $=20 \mu \mathrm{m}$ ). The inserts indicate positive immunoreaction; G. A histogram revealing the mean per cent of PCNA positive cells and area per cent of beclin 1 immunoreaction in the different groups; ${ }^{*} p<0.001$ ) comparing the HFrD with the control; ${ }^{\#} p<0.001$ comparing the HFrD + Ginger with the HFrD. Note: the table demonstrates the mean and standard deviation (SD) of the different groups. 
dilated rough endoplasmic reticulum with decrease in secretory granules. Baccetti et al. [16] declared that hyperglycaemia reduces the pituitary sensitivity to gonadotropin releasing hormone stimulation which subsequently affects the synthesis and release of FSH and LH. Further, Darbandi et al. [24] demonstrated that excessive production of ROS beyond that of cellular antioxidant capacity negatively affects male reproductive functions and may induce infertility via affecting the hypothalamus-pituitary-gonadal axis and hence affection of reproductive hormonal assay.

In this study, the hormonal assay also revealed a significant decrease in the testosterone hormone reflecting disrupted steroidogenesis by Leydig cells. This could be attributed to disruption in the pituitary function as clarified by Li et al. [44] who postulated the pivotal role of FSH in testicular development and $\mathrm{LH}$ in stimulating the biosynthesis of testosterone via its binding to Leydig cell. Moreover, de Lamirande et al. [25] clarified that free radical generation interrupts spermatogenesis and steroidogenesis directly and indirectly causing Leydig cell degeneration leading ultimately to a decline in testosterone secretion. This matches the structural changes observed in Leydig cells in this study.

Baccetti et al. [16] reported that all these hormonal changes affect spermatogenesis and sexual function. This may also explain degenerative changes of spermatogenetic cells, detected in this study, as clarified by Maneesh et al. [51]. Intraepithelial vacuolisation may be considered as a manifestation of testicular tubules' atrophy [87]. Sakr et al. [66] attributed the vacuolated cytoplasm of spermatogenic cells to lipid peroxidation causing damage to the cell membrane and membranes of the cell organelles with subsequent increase in their permeability.

Our results showed manifest histopathological changes in testicular specimens of HFrD-induced MetS group as compared to the control. The seminiferous tubules were shrunken, as confirmed morphometrically by the significant decrease in seminiferous tubule perimeter, and distorted with irregular outlines. This was consistent with the basement membrane irregularities detected by electron microscope and with the widened interstitial spaces. Similar results were reported by Meydanli et al. [52].

The presence of homogenous acidophilic material in the interstitial spaces, observed in this study, may be due to the lowered testosterone level thus increasing capillary filtration and interstitial fluid as postulated by Maddocks and Setchell [48]. Salama et al. [67], Ravikumar and Srikumar [63] attributed the presence of this material to the accumulation of free radicals and ROS resulting in increased vascular permeability as well as oozing of excess lymphatic exudates from degenerated lymphatic vessels. Lirdi et al. [46] concluded that alterations in the volume or composition of the interstitial fluid could significantly affect the testicular function. The decreased testosterone level may also explain blood vessel congestion, observed in this work, as testosterone plays a vital role in the regulation of testicular blood flow [89].

In the current work, ultrastructural findings further confirmed the damaging effect of HFrD-induced MetS on the testicular structure. Sertoli cells with damaged mitochondria, cytoplasmic vacuolation and increased lipid accumulation were frequently encountered. Anan et al. [13] reported that increased testicular oxidative stress was concomitant with impairment of Sertoli cells. Robeva et al. [64] have also reported, through clinical trials, that Sertoli cell function is suppressed in MetS. As Sertoli cells support and provide nutrition for the developing germ cells and are absolutely necessary for proper germ cell development and viability [55], Sertoli cell dysfunction reduces supportive capacity and impairs spermatogenesis and fertility [85]. Sertoli cell changes may also explain the abnormal presence of spermatids near the basement membrane as reported by Russell et al. [65] who suggested spermatids' phagocytosis by Sertoli cells and, then, failure of release.

In this study, widening of intercellular spaces among the germ cells as well as their separation from the basement membrane was noticed in most of the tubules. Mohamed et al. [53] suggested that exposure to ROS leads to disruption of tight junctions of blood-testis barrier with subsequent entry of excess water and toxic agents between the spermatogenic cells. Another explanation was given by Sugandhy et al. [75] who attributed the marked intercellular spacing to the sloughing and exfoliation of the spermatogenic cells into the lumen of the seminiferous tubules as a result of destruction of the cellular processes of Sertoli cells that fill the spaces between the germ cells. This corresponds with the significant reduction of germinal epithelium thickness observed in this study. Haubitz [32] declared that this thinning of the epithelium leads to defect in sperm production reflected, in this work, as marked affection of cross sections in the mid pieces of spermatozoal tails. Moreover, the 
middle pieces exhibited an excess retained cytoplasm, which can be attributed to the spermiogenesis arrest with subsequent interruption of cytoplasmic extrusion. Such spermatozoa are considered as immature and functionally defective spermatozoa as clarified by Malekinejad et al. [49].

Proliferating cell nuclear antigen, a nuclear protein required for DNA synthesis, is considered previously as a proliferation marker [41]. Since spermatogenesis is a complex cell cycle of rapidly proliferating cells ending with liberation of sperms, PCNA was previously used to quantitatively analyse spermatogenesis [2]. Decreased percentage of PCNA-positive immunostained cells was observed in testicular specimens of HFrD rats in this study. Xue et al. [86] related this to decreased DNA synthesis in the damaged testes. This is mostly attributed to ROS-induced DNA breakdown of spermatozoa which is commonly seen in infertile men as postulated by Bennetts and Aitken [18].

Autophagy is a master cellular process that helps cell survival from death stimuli through the removal of damaged organelles or proteins [38]. Additionally, autophagy decreases triglyceride and cholesterol accumulation, improves insulin signalling and prevents cellular injury from oxidative stress as reported by Liu et al. [47]. However, Zhang et al. [91] suggested that autophagy, when it occurs excessively or it is impaired, it may be deleterious and lead to activation of apoptosis-mediated cellular death. The autophagy process is regulated by a large group of autophagy-related proteins [26]. Beclin 1 is a $60-\mathrm{kDa}$ protein that can intervene at every major step in autophagic pathways through the activation of specific beclin 1-binding proteins [38].

High-fructose diet was previously reported to downregulate autophagy in liver tissue [90]. Moreover, Cha et al. [20] reported similar results in rat testis following doxorubicin treatment. These results match the results of our study where HFrD was found to downregulate beclin 1 immunostaining. This significant downregulation of beclin 1 in HFrD-induced MetS group could be linked to the affection of testicular functions as postulated by Tang and Wang [77] who stated that autophagy is considered as an important regulatory mechanism in spermatogenesis and steroid production in testis. This was in line with Gao et al. [27] who revealed that autophagy has been reported to be extremely active under normal conditions to promote cholesterol uptake into Leydig cells and hence testosterone production, suggesting that dysfunction of autophagy might be causal in the loss of testosterone production in some patients.

The current study provides evidence on the ability of ginger extract, at a dose of $500 \mathrm{mg} / \mathrm{kg} /$ day for 8 weeks, to alleviate HFrD-induced MetS adverse effects on the pituitary-gonadal axis of male rats. The results of this study revealed that ginger was able to restore testicular MDA and SOD activity. Moreover, exhibited glycaemic control and improved insulin sensitivity as indicated by the marked reduction of HOMA-IR index. It also corrected the dyslipidaemia through significantly decreasing the TG, LDL and increasing the HDL levels indicating its crucial role in controlling MetS. These improvements were accompanied by obvious attenuation of pituitary and testicular structural damage with significant increase in the testicular weight and the levels of reproductive hormones.

Consistent with our results, previous reports have indicated beneficial effects of ginger against HFrD accompanied unfavourable effects $[28,56]$. However, to the best of our knowledge, this is the first study to elucidate the effect of ginger on pituitary-gonadal axis changes resulting from HFrD-induced MetS.

The ameliorating effect of ginger can be attributed to its antioxidant properties through maintaining the activities of the antioxidant enzymes and scavenging the excessive ROS [5]. The antioxidant activity of ginger may be due to its high content of polyphenolic flavonoids (gingerols) which have also proven effectiveness against hyperlipidaemia [39, 88]. In line with this, previous researchers demonstrated that ginger positively modulated the antioxidant status of testis [12].

Narayanan and Jesudoss [57] considered ginger as one of the natural alternatives for the prevention of hyperlipidaemia. A possible explanation for its antihypertriglyceridaemic effect was provided by Platel and Srinivasan [59] who recorded that ginger, when added to animal diet, produces a considerable increase in pancreatic and intestinal lipase that plays a vital role in fat digestion. Al-Noory et al. [9] referred the increased HDL to the ginger content of niacin that reduces the catabolic rate of $\mathrm{HDL}$.

The anti-hyperglycaemic effect of ginger, observed in this study, was previously reported in other studies $[3,7]$. Khandouzi et al. [37] explained that ginger increases glucose uptake, glycogen synthesis and phosphorylation of the insulin receptor. Li et al. [43] added that ginger extract encouraged glucose uptake 
in cultured rat skeletal muscle cells. Ramakrishna et al. [62] reported that decreased blood glucose levels could be due to the free radical scavenging effect of ginger.

In match to our results, Arikawe et al. [14] stated that chronic fructose consumption caused structural alterations in pancreatic $\beta$ cells and hyperinsulinaemia and that this effect was reversed by ginger. This further confirms that ginger is a potent insulin sensitizer [80] and augments $\beta$ cell function [29].

In this work, ginger was demonstrated to restore the normal levels of reproductive hormones (LH, FSH and testosterone) that were downregulated by MetS. This can be explained by ginger's androgenic and antioxidant properties $[36,58]$ that were confirmed, in this work, by the significant improvement of the histomorphological features of the pituitary glands and testes. Similarly, Shalaby and Hamowieh [69] reported that ginger extract increased serum testosterone level and ameliorated histopathological lesions in the testes of diabetic rats.

The upregulating effect of ginger on PCNA expression, reported in this study, was consistent with previous reports which demonstrated a protective influence of 6-gingerol on DNA damage which is mostly mediated by (_OH) radical scavenging [45].

Moreover, ginger was indicated to significantly upregulate autophagy in the testes of rats of HFrD-induced MetS in this study. In line with our results, some recent reports have indicated that 6 -shogaol, a phytochemical of dietary ginger, might induce autophagic cell death in human non-small cell lung cancer A549 cells [33], hepatoma, breast and pancreatic cancer cell lines [6] and in human colon adenocarcinoma (HT-29) cells [42]. Li and Chiang [42] explained that 6-shogaol induced autophagic cell death through the formation of acidic vesicular organelles and autolysosomes.

\section{CONCLUSIONS}

In conclusion, the findings of our study indicated that HFrD MetS exhibited deleterious structural and functional alterations of the pituitary-testicular axis. Ginger was proved to have an obvious protective effect against these alterations through its antioxidant, hypoglycaemic, insulinotropic, androgenic and hypolipidaemic effects. Accordingly, it is highly recommended to avoid fructose overconsumption especially during adolescence. Moreover, ginger can be used as a dietary supplement to protect against MetS-related harmful effects on the pituitary-testicular axis. Additional experimental and clinical studies are needed to further contribute to the literature on the protective and therapeutic effects of ginger on the other metabolic syndrome associated derangements.

\section{Acknowledgements}

Work was conducted in: Faculty of Medicine, Cairo University, Cairo, Egypt; Faculty of Medicine, Menoufia University, Menoufia, Egypt; Faculty of Agriculture, Mansoura University, Mansoura, Egypt.

\section{REFERENCES}

1. Abarikwu SO, Pant AB, Farombi EO. Dietary antioxidant, quercetin, protects sertoli-germ cell coculture from atrazine-induced oxidative damage. J Biochem Mol Toxicol. 2012; 26(11): 477-485, doi: 10.1002/jbt.21449, indexed in Pubmed: 23132811.

2. Abdel-dayem MM. Histological and immunohistochemical changes in the adult rat testes after left experimental varicocele and possible protective effects of resveratrol. J Histol. 2009; 32(1): 81-90.

3. Afzali A, Ghalehkandi J. Effect of ginger, Zingiber officinale on sex hormones and certain biochemical parameters of male Wistar rats. Bioscien Biotechnol Res Com. 2018; 11(1): 181-186, doi: 10.21786/bbrc/11.1/25.

4. Aguilera-Mendez A, Hernández-Equihua MG, Rueda-Rocha $A C$, et al. Protective effect of supplementation with biotin against high-fructose-induced metabolic syndrome in rats. Nutr Res. 2018; 57: 86-96, doi: 10.1016/j.nutres.2018.06.007, indexed in Pubmed: 30122199.

5. Ahmed RS, Seth V, Banerjee BD. Influence of dietary ginger (Zingiber officinales Rosc) on antioxidant defense system in rat: comparison with ascorbic acid. Indian J Exp Biol. 2000; 38(6): 604-606, indexed in Pubmed: 11116533.

6. Akimoto M, lizuka M, Kanematsu $R$, et al. Anticancer effect of ginger extract against pancreatic cancer cells mainly through reactive oxygen species-mediated autotic cell death. PLoS One. 2015; 10(5): e0126605, doi: 10.1371/ journal.pone.0126605, indexed in Pubmed: 25961833.

7. Al-Amin ZM, Thomson M, Al-Qattan KK, et al. Anti-diabetic and hypolipidaemic properties of ginger (Zingiber officinale) in streptozotocin-induced diabetic rats. $\mathrm{Br}$ J Nutr. 2006; 96(4): 660-666, doi: 10.1079/bjn20061849, indexed in Pubmed: 17010224.

8. Al-Hamad D, Raman V. Metabolic syndrome in children and adolescents. Transl Pediatr. 2017; 6(4): 397-407, doi: 10.21037/tp.2017.10.02, indexed in Pubmed: 29184820.

9. Al-Noory AS, Amreen AN, Hymoor S. Antihyperlipidemic effects of ginger extracts in alloxan-induced diabetes and propylthiouracil-induced hypothyroidism in (rats). Pharmacognosy Res. 2013; 5(3): 157-161, doi: 10.4103/09748490.112419, indexed in Pubmed: 23901210.

10. Altabas V. Drug treatment of metabolic syndrome. Curr Clin Pharmacol. 2013; 8(3): 224-231, doi: 10.2174/15748 84711308030009, indexed in Pubmed: 22950955.

11. Alten B, Yesiltepe $M$, Bayraktar E, et al. High-fructose corn syrup consumption in adolescent rats causes bipolar-like behavioural phenotype with hyperexcitability in hippocampal CA3-CA1 synapses. Br J Pharmacol. 2018; 175(24): 4450-4463, doi: 10.1111/bph.14500, indexed in Pubmed: 30221753. 
12. Amin A, Hamza AA. Effects of Roselle and Ginger on cisplatin-induced reproductive toxicity in rats. Asian J Androl. 2006; 8(5): 607-612, doi: 10.1111/j.17457262.2006.00179.x, indexed in Pubmed: 16751998.

13. Anan H, Wahba N, Abdallah M, et al. Histological and immunohistochemical study of cyclophosphamide effect on adult rat testis. Int J Scien Rep. 2017; 3(2): 39, doi: 10.18203/issn.2454-2156.intjscirep20170356.

14. Arikawe AP, Oyerinde A, Olatunji-Bello II, et al. Streptozotocin diabetes and insulin resistance impairment of spermatogenesis in adult rat testis: central vs. local mechanism. Niger J Physiol Sci. 2012; 27(2): 171-179, indexed in Pubmed: 23652232.

15. Aydin S, Aksoy A, Aydin S, et al. Today's and yesterday's of pathophysiology: biochemistry of metabolic syndrome and animal models. Nutrition. 2014; 30(1): 1-9, doi: 10.1016/j. nut.2013.05.013, indexed in Pubmed: 24290591.

16. Baccetti B, La Marca A, Piomboni P, et al. Insulin-dependent diabetes in men is associated with hypothalamo-pituitary derangement and with impairment in semen quality. Hum Reprod. 2002; 17(10): 2673-2677, doi: 10.1093/humrep/17.10.2673, indexed in Pubmed: 12351547.

17. Basaranoglu M, Basaranoglu G, Sabuncu T, et al. Fructose as a key player in the development of fatty liver disease. World J Gastroenterol. 2013; 19(8): 1166-1172, doi: 10.3748/wjg.v19.i8.1166, indexed in Pubmed: 23482247.

18. Bennetts LE, Aitken RJ. A comparative study of oxidative DNA damage in mammalian spermatozoa. Mol Reprod Dev. 2005; 71(1): 77-87, doi: 10.1002/mrd.20285, indexed in Pubmed: 15736137.

19. Carrier A. Metabolic syndrome and oxidative stress: a complex relationship. Antioxid Redox Signal. 2017; 26(9): 429-431, doi: 10.1089/ars.2016.6929, indexed in Pubmed: 27796142.

20. Cha KM, Kopalli SR, Han SY, et al. Korean red ginseng attenuates doxorubicin-induced testicular dysfunction in rats by modulating inflammatory, oxidative, and autophagy responses. J Functional Foods. 2018; 40: 736-743.

21. Chandramohan R, Pari L. Protective effect of umbelliferone on high-fructose diet-induced insulin resistance and oxidative stress in rats. Biomedicine \& Aging Pathology. 2014; 4(1): 23-28, doi: 10.1016/j.biomag.2013.12.003.

22. Corona G, Mannucci E, Petrone L, et al. NCEP-ATP-III defined metabolic syndrome, type 2 diabetes mellitus and prevalence of hypogonadism in male patients with sexual dysfunction. J Sex Med. 2007; 4(4): 1038-1045.

23. Crescenzo R, Bianco F, Coppola P, et al. Adipose tissue remodeling in rats exhibiting fructose-induced obesity. Eur J Nutr. 2014; 53(2): 413-419, doi: 10.1007/s00394013-0538-2, indexed in Pubmed: 23728711.

24. Darbandi M, Darbandi S, Agarwal A, et al. Reactive oxygen species and male reproductive hormones. Reprod Biol Endocrinol. 2018; 16(1): 87, doi: 10.1186/s12958-0180406-2, indexed in Pubmed: 30205828.

25. de Lamirande $E$, Jiang $H$, Zini $A$, et al. Reactive oxygen species and sperm physiology. Rev Reprod. 1997; 2(1): 48-54, doi: 10.1530/ror.0.0020048, indexed in Pubmed: 9414465 .

26. Denton D, Xu T, Kumar S. Autophagy as a pro-death pathway. Immunol Cell Biol. 2015; 93(1): 35-42, doi: 10.1038/ icb.2014.85, indexed in Pubmed: 25331550.

27. Gao F, Li G, Liu C, et al. Autophagy regulates testosterone synthesis by facilitating cholesterol uptake in Leydig cells. J Cell Biol. 2018; 217(6): 2103-2119, doi: 10.1083/ jcb.201710078, indexed in Pubmed: 29618492.
28. Gao H, Guan T, Li C, et al. Treatment with ginger ameliorates fructose-induced Fatty liver and hypertriglyceridemia in rats: modulation of the hepatic carbohydrate response element-binding protein-mediated pathway. Evid Based Complement Alternat Med. 2012; 2012: 570948, doi: 10.1155/2012/570948, indexed in Pubmed: 23193424

29. Gastaldelli A, Ferrannini E, Miyazaki Y, et al. Thiazolidinediones improve beta-cell function in type 2 diabetic patients. Am J Physiol Endocrinol Metab. 2007; 292(3): E871-E883, doi: 10.1152/ajpendo.00551.2006, indexed in Pubmed: 17106061.

30. Guzmán-Gerónimo RI, Alarcón-Zavaleta TM, Oliart-Ros $\mathrm{RM}$, et al. Blue maize extract improves blood pressure, lipid profiles, and adipose tissue in high-sucrose diet-induced metabolic syndrome in rats. J Med Food. 2017; 20(2): 110-115, doi: 10.1089/jmf.2016.0087, indexed in Pubmed: 27977322.

31. Harrell CS, Burgado J, Kelly SD, et al. High-fructose diet during periadolescent development increases depressive-like behavior and remodels the hypothalamic transcriptome in male rats. Psychoneuroendocrinology. 2015; 62: 252-264, doi: 10.1016/j.psyneuen.2015.08.025, indexed in Pubmed: 26356038.

32. Haubitz M. Acute and long-ter toxicity of cyclophosphamide. Transplantationsmedizin. 2007; 19(2): 26.

33. Hung JY, Hsu YL, Li CT, et al. 6-Shogaol, an active constituent of dietary ginger, induces autophagy by inhibiting the AKT/mTOR pathway in human non-small cell lung cancer A549 cells. J Agric Food Chem. 2009; 57(20): 9809-9816, doi: 10.1021/jf902315e, indexed in Pubmed: 19799425.

34. Jang S, Jang BH, Ko $\mathrm{Y}$, et al. Herbal medicines for treating metabolic syndrome: a systematic review of randomized controlled trials. Evid Based Complement Alternat Med. 2016; 2016: 5936402, doi: 10.1155/2016/5936402, indexed in Pubmed: 27413388.

35. Johnson RJ, Segal MS, Sautin Y, et al. Potential role of sugar (fructose) in the epidemic of hypertension, obesity and the metabolic syndrome, diabetes, kidney disease, and cardiovascular disease. Am J Clin Nutr. 2007; 86(4): 899-906, doi: 10.1093/ajcn/86.4.899, indexed in Pubmed: 17921363.

36. Kamtchouing $P$, Mbongue Fandio GY, Dimo $T$, et al. Evaluation of androgenic activity of Zingiber officinale and Pentadiplandra brazzeana in male rats. Asian J Androl. 2002; 4(4): 299-301, indexed in Pubmed: 12508133.

37. Khandouzi N, Shidfar F, Rajab A, et al. The effects of ginger on fasting blood sugar, hemoglobin A1C, apolipoprotein B, apolipoprotein a-I and malondialdehyde in type 2 diabetic patients. Iran J Pharm Res. 2015; 14(1): 131-140, indexed in Pubmed: 25561919.

38. Kim I, Rodriguez-Enriquez S, Lemasters JJ. Selective degradation of mitochondria by mitophagy. Arch Biochem Biophys. 2007; 462(2): 245-253, doi: 10.1016/j. abb.2007.03.034, indexed in Pubmed: 17475204.

39. Kumarappan CT, Rao TN, Mandal SC. Polyphenolic extract of Ichnocarpus frutescens modifies hyperlipidemia status in diabetic rats. J Cell Mol Biol. 2007; 6(2): 175-187.

40. Kyathanahalli C, Bangalore S, Hanumanthappa K, et al. Experimental diabetes-induced testicular damage in prepubertal rats. J Diabetes. 2014; 6(1): 48-59, doi: 10.1111/17530407.12068, indexed in Pubmed: 23773549.

41. Lavezzi AM, Terni L, Matturri L. PCNA immunostaining as a valid alternative to tritiated thymidine-autoradiography 
to detect proliferative cell fraction in transitional cell bladder carcinomas. In Vivo. 2000; 14(3): 447-451, indexed in Pubmed: 10904880.

42. Li TY, Chiang BH. 6-shogaol induces autophagic cell death then triggered apoptosis in colorectal adenocarcinoma HT-29 cells. Biomed Pharmacother. 2017; 93: 208-217, doi: 10.1016/j.biopha.2017.06.038, indexed in Pubmed: 28641163.

43. Li Y, Tran VH, Duke CC, et al. Gingerols of Zingiber officinale enhance glucose uptake by increasing cell surface GLUT4 in cultured L6 myotubes. Planta Med. 2012; 78(14): 1549-1555, doi: 10.1055/s-0032-1315041, indexed in Pubmed: 22828920.

44. Li ZM, Liu N, Jiang YP, et al. Vitexin alleviates streptozotocin-induced sexual dysfunction and fertility impairments in male mice via modulating the hypothalamus-pituitary-gonadal axis. Chem Biol Interact. 2019; 297: 119-129, doi: 10.1016/j.cbi.2018.10.013, indexed in Pubmed: 30365938.

45. Lin J, Li X, Chen L, et al. Protective effect against hydroxyl radical-induced DNA damage and antioxidant mechanism of [6]-gingerol: A Chemical Study. Bull Korean Chem Soc. 2014; 35(6): 1633.

46. Lirdi LC, Stumpp T, Sasso-Cerri E, et al. Amifostine protective effect on cisplatin-treated rat testis. Anat Rec (Hoboken). 2008; 291(7): 797-808, doi: 10.1002/ar.20693, indexed in Pubmed: 18543292.

47. Liu C, Liao JZ, Li PY. Traditional Chinese herbal extracts inducing autophagy as a novel approach in therapy of nonalcoholic fatty liver disease. World J Gastroenterol. 2017; 23(11): 1964-1973, doi: 10.3748/wjg.v23.i11.1964, indexed in Pubmed: 28373762.

48. Maddocks S, Setchell BP. The composition of extracellular interstitial fluid collected with a push-pull cannula from the testes of adult rats. J Physiol. 1988; 407: 363-372, doi: 10.1113/jphysiol.1988.sp017420, indexed in Pubmed: 3256621.

49. Malekinejad H, Mirzakhani N, Razi M, et al. Protective effects of melatonin and Glycyrrhiza glabra extract on ochratoxin A-induced damages on testes in mature rats. Hum Exp Toxicol. 2011; 30(2): 110-123, doi: 10.1177/0960327110368416, indexed in Pubmed: 20413560.

50. Mamikutty N, Thent ZC, Sapri SR, et al. The establishment of metabolic syndrome model by induction of fructose drinking water in male Wistar rats. Biomed Res Int. 2014; 2014: 263897 , doi: $10.1155 / 2014 / 263897$, indexed in Pubmed: 25045660.

51. Maneesh $M$, Jayalakshmi $H$, Singh $T A$, et al. Impaired hypothalamic-pituitary-gonadal axis function in men with diabetes mellitus. Indian J Clin Biochem. 2006; 21(1): 165-168, doi: 10.1007/BF02913088, indexed in Pubmed: 23105591.

52. Meydanli EG, Gumusel A, Ozkan S, et al. Effects of resveratrol on high-fructose-induced testis injury in rats. Ultrastruct Pathol. 2018; 42(1): 65-73, doi: 10.1080/01 913123.2017.1397075, indexed in Pubmed: 29192848.

53. Mohamed D, Saber A, Omar A, et al. Effect of cadmium on the testes of adult albino rats and the ameliorating effect of zinc and vitamin E. Br J Scien. 2014; 11(1): 72-95.

54. Moreno-Fernández S, Garcés-Rimón M, Vera G, et al. High fat/high glucose diet induces metabolic syndrome in an experimental rat model. Nutrients. 2018; 10(10): 1502, doi: 10.3390/nu10101502, indexed in Pubmed: 30322196.

55. Murphy CJ, Richburg JH. Implications of Sertoli cell induced germ cell apoptosis to testicular pathology.
Spermatogenesis. 2014; 4(2): e979110, doi: 10.4161/2 1565562.2014.979110, indexed in Pubmed: 26413394.

56. Naidu JR, Zandra Z, Anthony V. Evaluation of antioxidant potential of zingerone against high fructose diet induced non-alcoholic steatohepatitis in rat model. Int Res J Pharmacy Med Scien. 2018; 1(4): 37-39.

57. Narayanan JM, Jesudoss VAS. Hepatoprotective potential of zingerone against nonalcoholic fatty liver disease in rats fed with fructose-enriched diet. Gen Physiol Biophys. 2016; 35(2): 185-194, doi: 10.4149/gpb_2015041, indexed in Pubmed: 26915720.

58. Oluwatoyin A. Physicochemical characterisation, and antioxidant properties of the seeds and oils of ginger (Zingiber officinale) and garlic (Allium sativum). Scien J Chem. 2014; 2(6): 44, doi: 10.11648/j.sjc.20140206.11.

59. Platel K, Srinivasan K. Influence of dietary spices and their active principles on pancreatic digestive enzymes in albino rats. Nahrung. 2000; 44(1): 42-46, doi: 10.1002/(SICI)1521-3803(20000101)44:1<42::AIDFOOD42>3.0.CO;2-D, indexed in Pubmed: 10702999.

60. Prabhakar P, Reeta KH, Maulik SK, et al. Protective effect of thymoquinone against high-fructose diet-induced metabolic syndrome in rats. Eur J Nutr. 2015; 54(7): 1117-1127, doi: 10.1007/s00394-014-0788-7, indexed in Pubmed: 25347965.

61. Putakala M, Gujjala S, Nukala S, et al. Cardioprotective effect of Phyllanthus amarus against high fructose diet induced myocardial and aortic stress in rat model. Biomed Pharmacother. 2017; 95: 1359-1368, doi: 10.1016/j.biopha.2017.09.054, indexed in Pubmed: 28946183.

62. Ramakrishna C, Shanmugam KR, Subbaiah GV, et al. Hepato-protective and antioxidant effect of ginger on hepatic tissue in experimental diabetic rats. Res J Pharmaceutical Biol Chem Scien. 2015; 6(5): 961-967.

63. Ravikumar S, Srikumar K. Metabolic dysregulation and inhibition of spermatogenesis by gibberellic acid in rat testicular cells. J Environ Biol. 2005; 26(3): 567-569, indexed in Pubmed: 16334298.

64. Robeva R, Tomova A, Kirilov G, et al. Anti-Müllerian hormone and inhibin B levels reflect altered Sertoli cell function in men with metabolic syndrome. Andrologia. 2012; 44 Suppl 1: 329-334, doi: 10.1111/j.14390272.2011.01185.x, indexed in Pubmed: 21749433.

65. Russell L, Ettlin R, Hikim A, et al. Histological and Histopathological Evaluation of the Testis. Int J Androl. 1993; 16(1): 83-83, doi: 10.1111/j.1365-2605.1993.tb01156.x.

66. Sakr S, Okdah Y, El-Abd S. Gibberellin A3 induced histological and histochemical alterations in the liver of albino rats. ScienceAsia. 2003; 29(4): 327-331, doi: 10.2306/ scienceasia1513-1874.2003.29.327.

67. Salama N, Bergh A, Damber JE. The changes in testicular vascular permeability during progression of the experimental varicocele. Eur Urol. 2003; 43(1): 84-91, doi: 10.1016/ s0302-2838(02)00501-8, indexed in Pubmed: 12507549.

68. Sekiwa Y, Kubota K, Kobayashi A. Isolation of novel glucosides related to gingerdiol from ginger and their antioxidative activities. J Agric Food Chem. 2000; 48(2): 373-377, doi: 10.1021/jf990674x, indexed in Pubmed: 10691642 .

69. Shalaby MA, Hamowieh AR. Safety and efficacy of Zingiber officinale roots on fertility of male diabetic rats. Food Chem Toxicol. 2010; 48(10): 2920-2924, doi: 10.1016/j. fct.2010.07.028, indexed in Pubmed: 20667464.

70. Shanmugam KR, Mallikarjuna K, Kesireddy N, et al. Neuroprotective effect of ginger on anti-oxidant enzymes in streptozotocin-induced diabetic rats. Food Chem Toxicol. 
2011; 49(4): 893-897, doi: 10.1016/j.fct.2010.12.013, indexed in Pubmed: 21184796.

71. Sharma R, Agarwal A. Role of reactive oxygen species in male infertility. Urology. 1996; 48(6): 835-850, doi: 10.1016/s0090-4295(96)00313-5.

72. Shawky NM, Shehatou GSG, Suddek GM, et al. Comparison of the effects of sulforaphane and pioglitazone on insulin resistance and associated dyslipidemia, hepatosteatosis, and endothelial dysfunction in fructose-fed rats. Environ Toxicol Pharmacol. 2019; 66: 43-54, doi: 10.1016/j. etap.2018.12.008, indexed in Pubmed: 30597379.

73. Spear LP. The adolescent brain and age-related behavioral manifestations. Neurosci Biobehav Rev. 2000; 24(4): 417-463, doi: 10.1016/s0149-7634(00)00014-2, indexed in Pubmed: 10817843.

74. Suga $A$, Hirano $T$, Kageyama $H$, et al. Effects of fructose and glucose on plasma leptin, insulin, and insulin resistance in lean and VMH-lesioned obese rats. Am J Physiol Endocrinol Metab. 2000; 278(4): E677-E683, doi: 10.1152/ ajpendo.2000.278.4.E677, indexed in Pubmed: 10751202.

75. Sugandhy O, Pannerdoss S, Suryavathi V. Toxic influence of mercuric chloride on antioxidant system in the testis and epididymis of albino rats. The 10th International Conference on Mercury as a Global Pollutant Halifax. 2011; 29: 45-100.

76. Sun SZ, Empie MW. Fructose metabolism in humans what isotopic tracer studies tell us. Nutr Metab (Lond). 2012; 9(1): 89, doi: 10.1186/1743-7075-9-89, indexed in Pubmed: 23031075.

77. Tang Z, Wang Z. Contribution of autophagy to the physiological and pathophysiological functions in the mammalian testis. Testes and Ovaries - Functional and Clinical Differences and Similarities. 2017, doi: 10.5772/67878.

78. Tappy L, Lê KA. Metabolic effects of fructose and the worldwide increase in obesity. Physiol Rev. 2010; 90(1): 23-46, doi: 10.1152/physrev.00019.2009, indexed in Pubmed: 20086073.

79. Tappy L, Lê KA, Tran C, et al. Fructose and metabolic diseases: new findings, new questions. Nutrition. 2010; 26(11-12): 1044-1049, doi: 10.1016/j.nut.2010.02.014, indexed in Pubmed: 20471804.

80. Triplitt C, Cersosimo E, DeFronzo RA. Pioglitazone and alogliptin combination therapy in type 2 diabetes: a pathophysiologically sound treatment. Vasc Health Risk Manag. 2010; 6: 671-690, doi: 10.2147/vhrm.s4852, indexed in Pubmed: 20859539.

81. Ulu R, Gozel N, Tuzcu M, et al. The effects of Mucuna pruriens on the renal oxidative stress and transcription factors in high-fructose-fed rats. Food Chem Toxicol. 2018;
118: 526-531, doi: 10.1016/j.fct.2018.05.061, indexed in Pubmed: 29860019.

82. Ventimiglia E, Capogrosso P, Colicchia M, et al. Metabolic syndrome in white European men presenting for primary couple's infertility: investigation of the clinical and reproductive burden. Andrology. 2016; 4(5): 944-951, doi: 10.1111/andr.12232, indexed in Pubmed: 27368157.

83. Vos MB, Kimmons JE, Gillespie C, et al. Dietary fructose consumption among US children and adults: the Third National Health and Nutrition Examination Survey. Medscape J Med. 2008; 10(7): 160, indexed in Pubmed: 18769702.

84. Wang J, Li D, Wang P, et al. Ginger prevents obesity through regulation of energy metabolism and activation of browning in high-fat diet-induced obese mice. J Nutr Biochem. 2019; 70: 105-115, doi: 10.1016/j.jnutbio.2019.05.001, indexed in Pubmed: 31200315.

85. Xu ML, Hu J, Guo BP, et al. Exploration of intrinsic and extrinsic apoptotic pathways in zearalenone-treated rat sertoli cells. Environ Toxicol. 2016; 31(12): 1731-1739, doi: 10.1002/tox.22175, indexed in Pubmed: 26460601.

86. Xue Ly, Zhang Xh, Xing Lx, et al. Serum hormone and cellular proliferation changes of testis in rats with experimental orchitis induced by lipopolysaccharide. J Reprod Contrac. 2007; 18(3): 181-186, doi: 10.1016/s10017844(07)60022-4.

87. Yamamoto CM, Hikim AP, Lue $Y$, et al. Impairment of spermatogenesis in transgenic mice with selective overexpression of $\mathrm{Bcl}-2$ in the somatic cells of the testis. J Androl. 2001; 22(6): 981-991, doi: 10.1002/j.1939-4640.2001. tb03439.x, indexed in Pubmed: 11700863.

88. Yen GC, Chang YC, Su SW. Antioxidant activity and active compounds of rice koji fermented with Aspergillus candidus. Food Chem. 2003; 83(1): 49-54, doi: 10.1016/ s0308-8146(03)00035-9.

89. Yousaf B, Liu G, Wang R, et al. Bisphenol A exposure and healing effects of Adiantum capillus-veneris $L$. plant extract (APE) in bisphenol A-induced reproductive toxicity in albino rats. Environ Sci Pollut Res Int. 2016; 23(12): 11645-11657, doi: 10.1007/s11356-016-6330-0, indexed in Pubmed: 26936479.

90. Zakaria S, ElBatsh M, Mowafy S. Effects of curcumin on autophagy and Nrf2 signaling pathway in a rat model of high fructose diet induced steatohepatitis. Bulletin of Egyptian Society for Physiological Sciences. 2017; 37(2): 208-226.

91. Zhang $Y$, Han Le, Yang $H$, et al. Bisphenol $A$ affects cell viability involved in autophagy and apoptosis in goat testis sertoli cell. Environ Toxicol Pharmacol. 2017; 55: 137-147, doi: 10.1016/j.etap.2017.07.014, indexed in Pubmed: 28846990. 